\title{
Tripoint Issues in Maritime Boundary Delimitation
}

\author{
COALTER G. LATHROP
}

\section{INTRODUCTION}

Tripoint issues arise in maritime boundary delimitation where the maritime areas of three coastal states converge and overlap. Where this trilateral geographic relationship exists, so too does the potential for a tripoint at which three bilateral maritime boundaries could intersect. The trilateral geographic relationship, although it need not necessarily result in a tripoint, creates a tripoint issue in the delimitation of each of the associated boundaries. Approximately one half of all maritime boundary delimitations worldwide involve a tripoint issue, ${ }^{1}$ and of the boundaries addressed in this series approximately two thirds involve at least one tripoint issue. ${ }^{2}$ For the purpose of this chapter the treatment of tripoints is limited to those that occur, or would occur, within 200 n.m. of the coasts of the three concerned states. $^{3}$ As more states extend jurisdiction beyond 200 n.m. with wide margin continental shelf claims, new tripoint relationships will arise. ${ }^{4}$

When a maritime boundary is delimited by negotiation or through judicial process, the primary concern of the negotiators, judges or arbitrators is to locate the boundary between the two parties to the negotiation or proceeding. However, where the delimitation takes place within 200 n.m. of third-state territory, a subsidiary question must also be answered: How should the endpoint(s) of the bilateral boundary be defined in light of possible third-state interests? The goal of this report is to provide the

1 Handbook on the Delimitation of Maritime Boundaries, UN Sales No. E.01.V.2 (2000) at 45.

2 Some of the boundaries addressed in these volumes, such as the boundary between France (Guadeloupe and Martinique)-Venezuela, involve up to four tripoints in a single agreement. See Report Number 2-11. However, the boundaries addressed in the following reports do not appear to contain any tripoint issues within 200 n.m.: 1-1, 1-2, 1-3, 1-5, 1-6, 3-1, 3-2, 3-3, 3-4, 3-5, 3-7, 3-8, 3-9, 4-3, 4-4, 4-5, 4-6, 4-13, 5-2, 5-7, 5-10, 5-18, 5-21, 5-26, 6-1, 6-21, 8-1, 8-3, 8-14, 9-2, 9-6, $9-24$.

3 The Cape Verde-Senegal-The Gambia, and the Australia-Papua New Guinea-Solomon Islands tripoints may be exceptions to this rule. See Report Numbers 4-2, 4-8, 5-3, 5-4, 5-16.

4 For example, tripoint issues beyond 200 n.m. will likely arise in the Gulf of Mexico's "Eastern Gap" where the continental shelves of Cuba, Mexico and the United States converge. See Report Numbers 1-4, 1-5, 2-8.

D.A. Colson and R.W. Smith (eds.), International Maritime Boundaries, 3305-3375.

(C) 2005. The American Society of International Law. Printed in the Netherlands. 
boundary practitioner with some answers to that question based on the maritime boundary delimitation practice of states, the International Court of Justice (ICJ) and maritime boundary tribunals. ${ }^{5}$

David Colson addressed tripoint issues briefly in his introductory chapter in Volume I. ${ }^{6}$ This report expands on Colson's analysis by addressing in greater detail the tripoint issues associated with maritime boundary delimitation generally, and by focusing specifically on the tripoint issues raised by the maritime boundary agreements reported in Volumes I-V. Colson identified five techniques used by delimiting parties to deal with tripoint issues. ${ }^{7}$ Four of those techniques are used in bilateral configurations and one is used in trilateral configurations. Colson's four bilateral techniques are: (1) creating an endpoint without explicit intent of future extension, ${ }^{8}$ (2) creating an endpoint on a final line segment, ${ }^{9}$ (3) creating an endpoint on an azimuth, ${ }^{10}$ and (4) creating an endpoint without prejudice to future extension. ${ }^{11}$ There is a fifth bilateral technique, creating an endpoint that is explicitly identified as the tripoint. This fifth technique is closely related to the first technique listed above, but it removes an element of uncertainty by specifying the exact nature of the endpoint, at least in the minds of the two delimiting states. Colson also identified one technique used in trilateral configurations: creating a tripoint through a negotiated trilateral agreement. ${ }^{12}$ For the purpose of analysis in this report, bilateral configurations and techniques are separated from trilateral configurations and techniques.

This report notes Colson's delimitation techniques, refines them slightly, adds a discussion about the evolving tripoint jurisprudence of international

5 State practice with regard to delimiting maritime boundaries in the presence of third states is quite robust. However, although the presence of a third state is often referred to in maritime boundary treaties and the literature notes third-state interests as one of the factors to be considered in delimitation, surprisingly little has been written on this topic. But see Rodman R. Bundy, State Practice in Maritime Delimitation, in 5 World Boundaries 18 (Gerald H. Blake ed., 1994) (additional factor to be taken into account); HandBook on the Delimitation of Maritime Boundaries, supra note 1 , at 45 ("[S]pecial attention should be given to the presence of the coasts of third States.").

6 David Colson, The Legal Regime of Maritime Boundary Agreements, in 1 INTERNATIONAL Maritime Boundaries 41 (Jonathan I. Charney \& Lewis M. Alexander eds., 1993).

$7 \quad$ Id. at $61-63$.

8 This is Colson's second technique. Id. at 61-62.

9 This is Colson's fifth technique. Id. at 63.

10 This is Colson's first technique. $I d$. at 61 .

11 This is Colson's fourth technique. Id. at 62-63.

12 This is Colson's third technique. Id. at 62. 
courts and tribunals, takes a closer look at the trilateral aspects of tripoint issues, and seeks to distinguish between the bilateral and trilateral perspectives.

The bilateral perspective is the perspective of the parties to a bilateral boundary agreement delimited by and binding on only the two parties. This is the perspective the parties to the bilateral agreement have on the tripoint as they sight down their shared line toward the third state. The trilateral perspective, on the other hand, is that of the three concerned states, nonparty states, judges, arbitrators, ocean users, academics, and others looking down from above, as on a map, at the actual or, more interestingly, the potential location and status of the tripoint. The two perspectives raise fundamentally different questions.

From the bilateral perspective the primary question is: How do the two parties conclude their bilateral agreement in light of known or presumed non-party, third-state interests? Specifically, how do they define the endpoint of their boundary in their bilateral boundary agreement? When the bilateral agreement is the first of three agreements associated with a potential tripoint, the two parties have relatively little information regarding the interests or boundary position of the third state. When the bilateral agreement is the second associated agreement, more information is available to the parties. By the time the third of three associated boundaries is delimited, the parties to the third agreement will already have delimited their boundaries with the third state. As a result of the previous two agreements, the third-state interests should be well known.

The level of information available to the delimiting parties will affect the way they define their endpoints. For example, the parties to the second and third associated agreements will have a geographical reference formed by the preceding agreement(s). They will know where the other boundary (or boundaries) end and on what terms because one or both of the parties will necessarily have been a party to an associated, preceding boundary with the third state. With this knowledge the parties have several options. They could avoid the tripoint by stopping short of the preceding boundary. ${ }^{13}$ They could create a complementary boundary, either by creating an endpoint coincident with an endpoint in the preceding boundary,${ }^{14}$ or by

13 For example, the Malaysia-Singapore boundary stops at point W25, well short of the endpoints on the preceding Indonesia-Malaysia and Indonesia-Singapore boundaries. See Report Numbers 5-20, 5-9, 5-11.

14 See Report Numbers 9-3(4) (France-United Kingdom), 9-16 (Belgium-France), 9-17 (BelgiumUnited Kingdom). 
specifying a direction for the last segment of their boundary that will intersect the preceding boundary at an unspecified, but identifiable point. ${ }^{15}$ Alternatively, parties to a second or third boundary could intentionally overstep the preceding boundary. ${ }^{16}$ These overlapping boundary situations are usually the result of a sovereignty dispute or disagreement as to delimitation method. Although there is great potential for more of them, these overlaps are currently rare in practice. ${ }^{17}$

Two parties to a bilateral boundary agreement can not create a boundary endpoint binding on the third state regardless of their endpoint technique. This is so even if the third state is mentioned in the bilateral agreement and the endpoint is referred to as the tripoint among the two parties and that third state. ${ }^{18}$ A bilateral agreement drafted in this way does not "trilateralize" the agreement and does not bind the third state. It may however indicate a high degree of understanding among the three states as to the location of the tripoint. This brings us to the second perspective the trilateral perspective.

From the trilateral perspective the primary questions are: (1) What is the trilateral geographic relationship? (2) How are the endpoints in the associated bilateral agreements defined? and (3) What does this information tell us about the status and likely location of the tripoint? In the event that the tripoint has been agreed among the three concerned states in a tripoint treaty, it becomes an actual tripoint. Assuming that no "fourth" state contests the tripoint agreement, the tripoint location and status are established and no further analysis is necessary. Although trilateral agreements are becoming more common, ${ }^{19}$ the vast majority of tripoints lack a trilateral agreement. Without a trilateral agreement, tripoints are only potential tripoints.

15 See Report Numbers 7-2 (Bahrain-Iran), 7-6 (Iran-Qatar), 7-13 (Bahrain-Qatar).

16 See Report Numbers 4-8 (Vol. IV) (Equatorial Guinea-Sao Tome and Principe), 4-11 (Gabon-Sao Tome and Principe).

17 There appear to be only three tripoint situations in which the second boundary oversteps the first boundary. They are the Colombia-Haiti-Jamaica, Dominican Republic-United States (Puerto Rico)-Venezuela, and Equatorial Guinea (Rio Muni)-Gabon-Sao Tome and Principe tripoints. The quadrilateral relationship among Barbados, Guyana, Trinidad and Tobago and Venezuela has also produced two conflicting treaties and the potential tripoints associated with those treaties have been identified as conflicting tripoints.

18 See Report Number 2-6 (Costa Rica-Panama).

19 At the time of this writing eight tripoint agreements have been concluded. See Report Numbers 6-7 (India-Indonesia-Thailand); 6-9 (India-Maldives-Sri Lanka); 6-11 (Add. 1) (India-Myanmar (Burma)-Thailand); 6-12 (Indonesia-Malaysia-Thailand); 10-12 (Poland-Sweden-Soviet Union); 10-17 (Estonia-Latvia-Sweden); 10-21 (Estonia-Finland-Sweden); and 11-4 (Azerbaijan-KazakhstanRussia). 
The status of potential tripoints falls along a spectrum of certainty. The least certain of potential tripoints are those that exist solely by virtue of the trilateral geographic relationship among three coastal states with overlapping maritime claims. ${ }^{20}$ These potential tripoints are not dealt with in this report because they are not yet associated with any boundary agreement. The most certain potential tripoints are those whose three associated bilateral agreements contain coincident endpoints. ${ }^{21}$ For these most certain of potential tripoints a trilateral agreement would amount to little more than a legalistic tidying up exercise. Nonetheless, without the trilateral agreement even the most certain potential tripoint is in fact only three coincident endpoints.

The bilateral and trilateral perspectives are closely related. The status and location of the actual or potential tripoint is dependent on the behavior of the three concerned states in their bilateral relationships. Conversely, the approach that parties to a bilateral agreement take to their endpoints is affected by previous bilateral agreements and by the status and location of the potential tripoint. Although the two perspectives are closely related, this report seeks to separate them for analytical clarity. Section II of this paper focuses on the bilateral perspective - that of parties, judges and arbitrators faced with a two-party delimitation in the presence of a non-party, third state. Section III and the accompanying table focus on the trilateral perspective - a look from above at the current status and likely location of tripoints in light of the coastal geography and existing bilateral agreements and judicial decisions.

\section{THE BILATERAL PERSPECTIVE}

With regard to tripoint issues, the first step for parties to a bilateral maritime boundary delimitation is to determine whether any third-state interests exist. As noted above, approximately one-third of the boundary agreements reported in these volumes do not involve any third-state interests. The lack of third-state interests simplifies matters immensely. For the other two-

20 Examples of potential tripoints that exist only by virtue of trilateral geographic relationships are: Bangladesh-Burma-India; Djibouti-Somalia-Yemen; Algeria-Morocco-Spain; Bahamas-HaitiUnited Kingdom (Turks and Caicos); and Indonesia-Malaysia-Philippines.

21 See, e.g., Report Numbers 5-1 (Australia-France (New Caledonia)), 5-4 (Australia-Solomon Islands), 5-17 (France (New Caledonia)-Solomon Islands). 
thirds, the presence of a third state is a complicating factor that must be addressed.

Identifying the existence of tripoint issues, if any, is discussed in Section A. Once third-state interests have been identified, the parties must decide how to address those interests in the definition of their boundary. The five techniques used by delimiting states to deal with third-state interests are discussed in Section B. Finally, international courts and tribunals tasked with delimitation between two parties often find themselves faced with non-party, third-state interests. How courts and tribunals have dealt with tripoint issues in the seven cases in which they have arisen is discussed in Section C.

\section{A Identifying Tripoint Issues}

The parties to a bilateral delimitation must first determine whether a tripoint issue exists, with which third state, and what the nature of the issue is. Where one or both parties have delimited their boundary with the third state, the third-state interests may already be clear. This gives the parties to the present delimitation something to meet up with, to avoid, or if there are overlapping claims, to purposely overstep. In the absence of any preexisting delimitations, the parties should rely in the first instance on the coastal geography to determine whether and with whom they have a trilateral geographic relationship.

Where two adjacent coastal states face toward areas of open ocean, unimpeded by third-state territory or maritime claims, tripoint relationships do not arise. ${ }^{22}$ However, in areas with constricted coastal relationships, such as semi-enclosed seas, or concave coastlines, the maritime areas of most coastal states overlap the claims of at least two other coastal states and tripoint relationships abound. ${ }^{23}$ In an equidistant world devoid of sovereignty disputes, it would be clear which states have tripoint relationships with each other and where those tripoints would be located. The reality is that unresolved territorial disputes and claims to maritime area beyond equidistant lines create significant uncertainty, not only with regard to the loca-

22 The South American region, for example, has only one tripoint. See generally Region III boundary reports, documents and regional analyses in this series.

23 The Middle America and Caribbean region has 32 tripoints. See generally Region II boundary reports, documents and regional analyses in this series. 
tion of a potential tripoint, but more fundamentally, with regard to the very existence of a tripoint relationship in the first place.

\section{Coastal Relationships}

The first step in determining whether a trilateral geographic relationship exists is to measure distances from coasts. Wide margin continental shelf claims aside, State A will not have a maritime boundary relationship with State B unless their coasts are within 400 n.m. of each other. If State B is within 400 n.m. of State A, the second step is to determine whether a third state, State C, is within 400 n.m. of both State A and State B. If so, States $\mathrm{A}, \mathrm{B}$, and $\mathrm{C}$ have a trilateral geographic relationship that creates a potential tripoint. Although it is sound policy for a state to begin its analysis this way, this approach assumes that all three states view their boundary relationships in terms of equidistance. Until the boundary positions of all three states are ascertained and agreed, some uncertainty will still exist.

A classic illustration of this uncertainty is the changing relationship among the North Sea states of Germany, Denmark and the Netherlands from the 1960s to the early 1970s. ${ }^{24}$ In 1966 Denmark and the Netherlands delimited an equidistant boundary taking into account the existence of the two neighboring states - the United Kingdom to the west and Germany to the east. ${ }^{25}$ At the western end of their boundary the parties created an endpoint that coincided with the northern endpoint of the Netherlands-United Kingdom boundary and the southern endpoint of the Denmark-United Kingdom boundary. ${ }^{26}$ At the eastern end of their boundary Denmark and the Netherlands created an endpoint that was equidistant from the coasts of Denmark, Germany and the Netherlands. ${ }^{27}$ On the basis of equidistance applied to the coastal configuration of the North Sea, the Netherlands and Denmark assumed a Denmark-Germany-Netherlands tripoint relationship and a Denmark-Netherlands-United Kingdom tripoint relationship. With hindsight we see that neither relationship endured. Germany's successful equity claim before the ICJ overcame its neighbors' equidistance presumptions and obtained for Germany a much larger piece of the North Sea than it

24 Colson mentions this same example in his Vol. I chapter as an illustration of "the danger in assuming the views of a third state." Colson, supra note 6 , at 63 . The danger is that tripoint relationships assumed to exist in fact do not.

25 Report Number 9-18.

26 Report Numbers 9-10, 9-13, 9-18.

27 Report Number 9-18 at 2499.
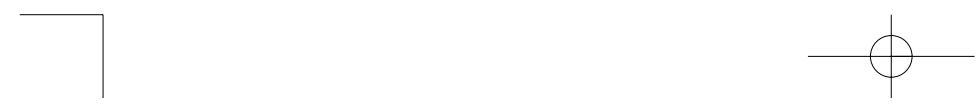
would otherwise have received. As a result of subsequent Denmark-Germany and Germany-Netherlands boundary agreements, concluded in the early 1970s, the two tripoint relationships created by the Denmark-Netherlands boundary were extinguished and two new tripoint relationships, not previously contemplated, were created: Denmark-Germany-United Kingdom and Germany-Netherlands-United Kingdom. ${ }^{28}$

The geographic relationship among the coasts of the concerned states is still the appropriate starting point for identifying tripoint issues. The above illustration is merely a cautionary tale for those who assume too much about their neighbors.

\section{Sovereignty Disputes}

The uncertainty exemplified in the relationship among Denmark, Germany, and the Netherlands, where there was no disputed coastal territory, is exacerbated by sovereignty disputes over coastal territory, including islands. Often sovereignty disputes create uncertainty as to the location of a tripoint, but do not alter which states are involved in the tripoint relationship. This is so among Equatorial Guinea, Gabon and Sao Tome and Principe. The long-standing sovereignty dispute over several small islands in Corisco Bay has delayed delimitation of the Equatorial Guinea-Gabon boundary and thus the tripoint among the three states. The outcome of this sovereignty dispute could impact the location of the tripoint, but the trilateral relationship will still be among those three states. A similar situation exists among Indonesia, Malaysia and Singapore and the sovereignty dispute over Pedra Branca/Pulau Batu Puteh. ${ }^{29}$ As a result of that dispute, the location and number of the tripoints is uncertain. ${ }^{30}$ That the tripoint(s) will be among Indonesia, Malaysia and Singapore is not.

This is not always so. There are situations in which the outcome of a sovereignty dispute will alter both the location of the tripoint and which

28 Report Numbers 9-8 and 9-11.

29 See ICJ Press Release 2003/22 (July 24, 2003); Joint Notification to the Registrar of the International Court of Justice of the Dispute between Malaysia and Singapore Concerning Sovereignty over Pedra Branca/Pulau Batu Puteh, Middle Rocks and South Ledge (July 24, 2003), available at http://www.icj-cij.org/ecjwww/idocket/imasi/imasiorder/imasi_iapplication_20030724.pdf (last visited Oct. 27, 2004).

30 If Singapore is sovereign over Pedra Branca/Pulau Batu Puteh, there could be three IndonesiaMalaysia-Singapore tripoints in the eastern Singapore Strait. If Malaysia is sovereign, there would be only one. Regardless of the outcome in this territorial sovereignty case, there will also be an Indonesia-Malaysia-Singapore tripoint in the west near the confluence of the Singapore, Malacca and Johor Straits. 
states are involved in the tripoint relationship. For example, the outcome in the dispute between Japan and South Korea over Takeshima/Dokto could affect the location of the tripoint, but it could also determine whether Japan and South Korea have a tripoint relationship with North Korea or with Russia. Similarly, the outcome of the sovereignty dispute between Guyana and Venezuela over the Essequibo region could determine whether Guyana has tripoint relationships with Trinidad and Tobago or Barbados, or no tripoint relationships at all.

\section{B Drafting Options}

Colson identified four techniques that states use to address tripoint issues that arise during bilateral delimitations. This report adds a fifth technique and provides a stylized, but descriptive, symbol to represent each technique. ${ }^{31}$ In Sections 1 through 5 below these bilateral techniques are described in more detail, and examples from actual treaty texts are provided. The techniques are listed in decreasing order of certainty with regard to the location of their associated potential tripoint. The first and second techniques create well-defined endpoints that may or may not become actual tripoints through further agreement. The third and fourth techniques create undefined, floating endpoints that are often described in reference to a third state and which will only become well-defined points as a result of agreement with that state. The fifth technique creates a welldefined, but probably temporary endpoint, beyond which the parties intend to extend their boundary in the future.

\section{Tripoint Identified}

Using this technique the two delimiting states take it upon themselves to define their tripoint even in the absence of the third state. Often the parties will refer to the third state by name. However, merely calling an endpoint of a bilateral boundary a tripoint does not "trilateralize" the agreement, even if the third state is named explicitly. Nevertheless, this drafting technique does clarify the intentions of the two parties with regard

31 These symbols are used in the accompanying table as a shorthand for designating the endpoint technique in each agreement. 
to the third state and may indicate some degree of trilateral understanding. Below are three examples.

The 2003 Cape Verde-Mauritania boundary agreement uses this technique. Article 6 describes the southern endpoint of this boundary as follows: "[P]oint $\mathrm{H}$. . . constitutes a tripartite frontier point for the Republic of Cape Verde, the Islamic Republic of Mauritania and the Republic of Senegal." "32 This point is nearly coincident with point H of the 1993 boundary between Cape Verde and Senegal. ${ }^{33}$ However, there is no associated trilateral agreement, and no boundary between Mauritania and Senegal has yet been agreed.

The 2002 Kazakhstan-Russia boundary treaty also uses this technique. Article 1 describes the endpoint in the Caspian Sea in the following manner: "The endpoint of the modified median line is the point with coordinates $42^{\circ} 33.6^{\prime} \mathrm{N}$ and $49^{\circ} 53.3^{\prime}$ E.... The above point may be taken as the junction point of the lines of demarcation of the Caspian seabed... among the Republic of Kazakhstan, the Russian Federation and the Azerbaijani Republic, which will be recorded in a trilateral agreement among them." ${ }^{34}$ The agreement between Kazakhstan and Russia was the first agreement associated with the Azerbaijan-Kazakhstan-Russia tripoint. That this language was included in the first of three bilateral agreements could indicate previous diplomatic correspondence on the tripoint issue among the three states.

The 1971 Denmark-United Kingdom boundary treaty also uses this technique. After providing the coordinates of the endpoints in Article 2, Article 3 provides that "[i]n the north the termination point of the dividing line is the point of intersection of the dividing lines between the Continental Shelves of the Kingdom of Denmark, the United Kingdom of Great Britain and Northern Ireland and the Kingdom of Norway." 35 This endpoint is coincident with endpoints in the 1965 Denmark-Norway agreement and the 1965 Norway-United Kingdom agreement, although no tripoint agreement has been concluded. This linguistic formula is repeated in many of the other North Sea boundary treaties.

Report Number 4-12 in this volume.

Report Number 4-8 (Vol. III).

Report Number 11-2 in this volume.

Report Number 9-10 at 1833-34. 


\section{Endpoint without Explicit Intent of Future Extension}

This technique allows the two delimiting states to define their endpoint without calling it a tripoint or referring to third states. Although the endpoint is clearly defined, a question remains as to its status in the minds of the delimiting states. Because they express no intent to extend their boundary beyond the endpoint, the endpoint could represent their version of a tripoint. However, mere silence does not preclude future extension, and the tripoint ultimately could be located beyond the delimiting parties' endpoint. ${ }^{36}$ This technique usually takes the form of a list of coordinates to be connected by straight lines without reference to any extension beyond the first or last points in the list. Below are two examples.

The 1977 Cuba-United States boundary agreement uses this technique. Article 1 begins: "The maritime boundary between the United States of America and the Republic of Cuba shall be determined by the geodetic lines connecting the following coordinates." ${ }^{37}$ The treaty then supplies a list of coordinates for 27 turning points without mention of a third state or the possibility of future extension beyond points 1 or 27 . Of course, there is a third state present in the vicinity of point 1 - the Bahamas - but neither party had concluded a boundary agreement with the Bahamas at the time of their agreement. Point 1 of the United States-Cuba boundary is

36 States need not reserve the right to extend their boundary in order to extend it in the future. However, for the purposes of this analysis and for the sake of consistency in categorization of these agreements, this study assumes no intent to extend unless that intent is explicit in the text of the agreement. This purely textual approach can produce results inconsistent with reality. For example, although Japan and South Korea do not refer in their boundary treaty to the future extension of their boundary beyond the northernmost point, point 35, one can assume that the parties intend to extend their boundary after resolution of their sovereignty dispute over Dokto/Takeshima. See Report Number 5-12.

The territorial sea boundary agreement between France and Italy provides another example of a treaty in which the endpoints clearly do not coincide with the parties' notion of final endpoints. Although the agreement clearly is limited to the territorial sea and ends at the outer limits of that zone, because it does not indicate an explicit intent to extend beyond those endpoints it is assigned the technique of endpoint without explicit intent of future extension. See Report Number $8-2$.

Some treaties indicate that they are limited to a specific geographic area. The implication is that there is still more boundary to be delimited outside that geographic area. This is so in the boundary agreement between China and Vietnam, which creates a boundary "between the two countries in the Tonkin Gulf (emphasis added)." Report Number 5-25 in this volume. Nonetheless, because there is no explicit intent to extend the boundary beyond the Tonkin Gulf, the agreement is assigned the endpoint without explicit intent of future extension technique.

37 Report Number $1-4$ at 423. 
equidistant from the parties and the Bahamas. ${ }^{38}$ Although this may signal the parties' intent to delimit an equidistant tripoint with the Bahamas, the final location of the Bahamas-Cuba-United States tripoint is still open to negotiation.

The 1990 France (New Caledonia)-Solomon Islands boundary agreement also uses this technique. Article 1 provides that "[t]he line of delimitation of maritime areas between the Solomon Islands and the French Republic is the line which lies along the loxodromes connecting the point [sic] defined by their coordinates as follows." ${ }^{39}$ A list of four sets of coordinates for points 23 through 26a follows. Although the third state - here Australia - is not mentioned, nor is there any reference to a tripoint, in fact point 23 coincides with the endpoints of the two preceding, associated treaties - Australia-France (New Caledonia), and Australia-Solomon Islands. ${ }^{40}$ Here, France and the Solomon Islands clearly intended to create a boundary in harmony with the two foregoing agreed boundaries.

\section{Endpoint on Final Line Segment `.}

This technique creates a floating, undefined endpoint located somewhere along a defined final line segment. Using this technique, the delimiting parties define a penultimate turning point and a range point as the starting and ending points of the final line segment. The parties also usually define the nature of the line segment itself. For example, the line segment may be defined as a geodetic line, an arc of maximum circumference, or a loxodrome often with a specified azimuth or direction. If the parties use an azimuth to define the nature of the final line segment, it does not matter whether the azimuth is defined from the penultimate turning point toward the range point ${ }^{41}$ or from the range point back to the penultimate turning point. ${ }^{42}$ The result is still a line segment between the penultimate turning point and the range point along which the endpoint of the bilateral agreement will be located. In most instances, this technique is used purposefully by parties to a boundary negotiation as a way to define a range of possible tripoint locations. However, the balkanization of Yugoslavia and the

38 Id. at 420; Limits in the Sea No. 110, Maritime Boundary: Cuba-United States, US DOS, Bureau of Oceans and International Environmental and Scientific Affairs, February 21, 1990, at 3.

39 Report Number 5-17 at 1172.

40 Report Numbers 5-1, 5-4.

41 Report Number 2-14.

42 Report Number 7-2. 
Soviet Union unintentionally has created similar boundary configurations in the Adriatic, Baltic and Black Seas. ${ }^{43}$ Below are three examples.

This is a popular drafting technique in the Caribbean and is used repeatedly by both Colombia and Venezuela. The 1978 United States (Puerto Rico and the Virgin Islands)-Venezuela boundary treaty uses this technique. Article 2 states that the western end of that boundary is formed by a line on "an azimuth of 274.23 degrees true from point 22 [penultimate turning point], in the event the maritime boundary of the United States of America extends westward, until the tri-junction with a third State is reached. In no case shall this tri-junction point be further westward than [15 $15^{\circ} 14^{\prime} 28^{\prime \prime} \mathrm{N}, 68^{\circ} 51^{\prime} 44^{\prime \prime} \mathrm{W}$ ] [range point]." ${ }^{\prime 4}$ This description appears to conflict with the endpoint described in the associated bilateral agreement between the Dominican Republic and Venezuela. ${ }^{45}$

43 For example, the Soviet Union and Turkey concluded a series of boundary agreements in the Black Sea from their land boundary terminus in the east to a potential tripoint in the west. As is normally the case, the resulting boundary line consisted of a series of line segments defined by turning points. With the dissolution of the Soviet Union, one coastal state became three Georgia, Russia and Ukraine. As successors to the Soviet Union, all three have committed to respecting the boundary agreements of the Soviet Union, including those with Turkey in the Black Sea. Report Numbers 8-10(4) and (5). Although the boundary between Turkey and its three northern neighbors is complete, because there are not yet any adjacent boundaries between Georgia and Russia and between Russia and Ukraine, it is not clear where the tripoints will be located. It is clear, however, that the tripoints will be located on line segments defined in the original agreements between the Soviet Union and Turkey. Therefore, the unintentional creation of final line segments is similar to the purposeful use of this technique.

Essentially the same series of events has occurred in the Adriatic Sea originally between Italy and Yugoslavia and subsequently between Italy on the one hand and Slovenia, Croatia and Serbia and Montenegro on the other. See Report Number 8-7(3). Bosnia-Herzegovina is zone-locked by Croatia. Report Number 8-14.

As a successor to the Soviet Union, Russia's situation in the Baltic Sea, with respect to Finland and Sweden, is similar to its situation with Turkey in the Black Sea. See Report Numbers 104(1), (2), (3), (4) and 10-9.

44 Report Number 2-14 at 702. Note the conditional clause in this provision which indicates that point 22 could be the endpoint without further extension.

45 In the corresponding Dominican Republic-Venezuela boundary treaty concluded the following year the parties describe the eastern sector of their boundary (Sector B) using the same points (United States-Venezuela point 22 and the United States-Venezuela range point). The description of Sector B is: "Starting from point 7, [15 $\left.15^{\circ} 4^{\prime} 28^{\prime \prime} \mathrm{N}, 68^{\circ} 51^{\prime} 44^{\prime \prime} \mathrm{W}\right]$, a geodesic line whose azimuth is $94^{\circ}, 13, \ldots$ to a point at $\left[15^{\circ} 12^{\prime} 51^{\prime \prime} \mathrm{N}, 68^{\circ} 28^{\prime} 56^{\prime \prime} \mathrm{W}\right] . "$ Report Number 2-9 at 589. This description raises three problems. First, a geodetic line, with rare exceptions, has a constantly changing direction and so cannot accurately be described by a single azimuth. Second, if this final segment is a geodesic line connecting the two points, it will not coincide throughout its length with the loxodrome described in the United States-Venezuela treaty. Third, and most importantly, is the use of the word "to" in the United States-Venezuela treaty. If "to" means "toward," the Dominican Republic-Venezuela boundary could be seen as consistent with the corresponding United States-Venezuela boundary. However, if "to" means that the boundary reaches 
The 1978 Netherlands (Saba and Saint Eustatius)-Venezuela (Aves) boundary agreement uses this technique to describe the endpoints of Sector D. Article 2 describes the eastern endpoint of Sector D in this way: "From point No. 15, an arc of maximum circumference to point No. $16\left[16^{\circ} 40^{\prime}\right.$ $01^{\prime \prime} \mathrm{N}, 63^{\circ} 35^{\prime} 20^{\prime \prime} \mathrm{W}$, or that point on said maximum circumference that represents the boundary with third nations." 46

The 1971 Bahrain-Iran boundary treaty uses this technique. In relevant part, Article 1 states: "Point (1) [floating endpoint] is the Eastern-most point on the Eastern-most part of the Northern boundary line of the continental shelf appertaining to Bahrain as formed by the intersection of a line

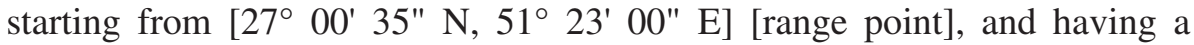
geodetic azimuth of 278 degrees, 14 minutes, 27 seconds, with a boundary line dividing the continental shelf appertaining to Bahrain and Qatar, thence" point 2 [penultimate turning point] ${ }^{47}$ The range point and azimuth are identical to the penultimate turning point and azimuth in the neighboring Iran-Qatar boundary agreement concluded two years earlier in 1969. The use of this technique by Bahrain and Iran in conjunction with the previous Iran-Qatar agreement created an agreed line segment between the range point and penultimate turning point along which the Bahrain-IranQatar tripoint is theoretically located. The recent ICJ decision in the case between Bahrain and Qatar creates an azimuth that points toward the agreed line segment and the potential Bahrain-Iran-Qatar tripoint.

\section{Endpoint on Azimuth \...}

This technique creates a floating, undefined endpoint located somewhere along a defined azimuth. Parties using this technique define a penultimate turning point and an azimuth, but do not define a range point and therefore do not limit the distance along the azimuth at which the endpoint could be located. This technique provides a compromise between, on the one hand, leaving the final segment of a boundary entirely undefined for lack of third-state participation and, on the other hand, creating a defined final endpoint that may be challenged by the third state. For this reason, this

the second point, a point identical to point 22 of the United States-Venezuela boundary, then this treaty indicates an intent to create a fixed endpoint located at the second point (United StatesVenezuela point 22), rather than a floating endpoint located short of point 22.

46 Report Number 2-12 at 633

47 Report Number 7-2 at 1487. 
technique is often used in the third-party settlement of maritime boundary disputes. Below are two examples.

The 1999 Latvia-Lithuania maritime boundary treaty uses this technique to describe the last segment of the boundary. Article 2 defines the final segment of the Latvia-Lithuania boundary: "The boundary ... shall be a straight line (loxodrome) in the azimuth of 270 (two hundred seventy degrees) running from the point II [penultimate turning point] defined in the Article 1 towards the boundary of the exclusive economic zone and continental shelf of the third State." ${ }^{48}$

The 2000 Saudi Arabia-Yemen maritime boundary treaty also uses this technique. In Annex 3 the final segment of the boundary as it approaches a potential tripoint with Eritrea is described in the following manner: "From there $\left[16^{\circ} 17^{\prime} 24^{\prime \prime} \mathrm{N}, 41^{\circ} 47^{\prime} 00^{\prime \prime} \mathrm{E}\right.$, it proceeds] in a straight line parallel to the latitudes in the direction of west until the terminus of the maritime boundaries between the two countries." ${ }^{49}$ This language provides information about the latitude of the endpoint $\left(16^{\circ} 17^{\prime} 24^{\prime \prime} \mathrm{N}\right)$ but does not provide information about the location of the tripoint along that parallel other than that it is west of $41^{\circ} 47^{\prime} 00^{\prime \prime} \mathrm{E}$. How far west will be determined by the location of the as yet undelimited Eritrea-Saudi Arabia boundary to the north and the partially delimited Eritrea-Yemen boundary to the south..$^{50}$

\section{Endpoint without Prejudice to Future Extension $?$}

This final technique can be divided into two sub-techniques, both of which create ambiguity around the endpoint of a boundary line. The first subtechnique - the fuzzy azimuth - resembles the defined azimuth technique just described. However, instead of providing an azimuth in terms of degrees or by combining a general direction with other specific information, ${ }^{51}$ this sub-technique provides only a general direction for the possible future extension of the boundary. The second sub-technique - the ambivalent endpoint - resembles the endpoint without explicit intent of future extension technique described above except that here the parties explicitly

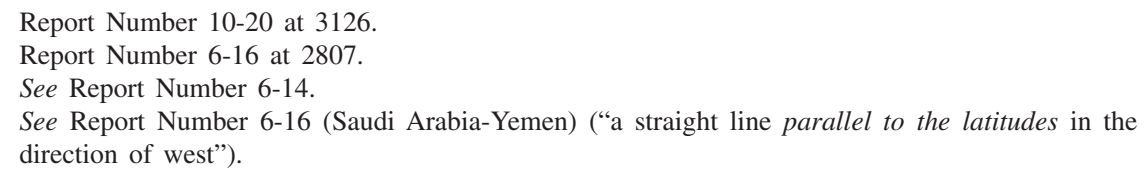


reserve the right to extend the boundary or to revise the endpoint. ${ }^{52}$ These two sub-techniques often are used together. Because this fifth technique contemplates an extension, or at least a revision, of the boundary, but does not provide the specific direction nor the maximum distance of the extension, this technique results in more ambiguity as to the likely location of the tripoint than any of the techniques above. It also reserves the most flexibility for the delimiting states and as a result is a popular technique. Below are five examples.

Article 2 of the 2001 Honduras-United Kingdom (Cayman Islands) boundary treaty uses a combination of the fuzzy azimuth and ambivalent endpoint sub-techniques. After describing three turning points $\mathrm{A}, \mathrm{B}$, and $\mathrm{C}$ in Article 1, Article 2 describes the line beyond point $\mathrm{C}$ in the following manner: "It has not been possible, for the time being, to complete the maritime delimitation beyond point $\mathrm{C}$. It is, however, agreed between the Parties that the delimitation from point $\mathrm{C}$ shall, at the appropriate time, be continued in an easterly direction until it meets the tripoint between the limits of the maritime areas under the respective jurisdictions of the Parties and another State's jurisdiction." ${ }^{53}$

The 1977 Greece-Italy boundary treaty also contains elements of both sub-techniques. Article 1, paragraph 3 states: "The Contracting Parties have agreed that for the moment such delimitation shall not extend northward beyond point 1 or southward beyond point 16. This delimitation shall subsequently extend in both directions to the points of intersection with the zones of the continental shelf belonging to the respective neighboring countries." ${ }^{54}$

Article 2, paragraph 2 of the 1974 Italy-Spain boundary treaty contains similar language: "The Contracting Parties agree that, for the moment, the delimitation will not extend north further than point $\mathrm{A}$, and south further than point L." ${ }^{55}$

52 Some texts are more explicit than others in indicating their intent to extend beyond their final endpoint. This study has made the greatest effort to be consistent in the categorization of those agreements that use the second technique - no explicit intent to extend - and those that use this sub-technique - ambivalent endpoint.

53 Report Number 2-23 in this volume. It appears that the third state could be either Colombia, Jamaica or Nicaragua, depending upon the outcome of two cases currently before the ICJ (Nicaragua v. Honduras and Nicaragua v. Colombia) and also upon Jamaica's boundary position with regard to its nearest neighbor to the south, which ever state that turns out to be.

54 Report Number 8-4 at 1599.

55 Report Number 8-5 at 1607. 
The 2000 Equatorial Guinea-Nigeria boundary treaty uses the ambiguity created by this technique to protect the parties' interests while avoiding a contemporaneous ICJ boundary case. Article 3 reads: "Northwards and eastwards from Point (i) identified in Article 2 the maritime boundary shall be established by the Contracting Parties ... following completion of the maritime aspects of the case before the International Court of Justice between the Federal Republic of Nigera and the Republic of Cameroon...." ${ }^{56}$ As with the Italian examples, the parties contemplate a future extension of the boundary beyond a defined endpoint.

Article 1 of the 2003 Cyprus-Egypt boundary treaty uses the ambivalent endpoint sub-technique. Regarding the future disposition of their endpoints, the parties agreed that "the geographical coordinates of points 1 and 8 could be reviewed and/or extended as necessary in light of future delimitation of the EEZ with other concerned neighboring states and in accordance with an agreement to be reached in this matter by neighboring states concerned." ${ }^{57}$ Unlike the above examples of this technique, the use of the word "review" seems to leave open the possibility of shortening, rather than extending, the final segments of this boundary.

\section{Practice of the Court and Tribunals}

The ICJ and boundary tribunals have been cautious about prejudicing the interests of non-party third states by overstepping the claims of those states in their boundary decisions. While the ICJ and tribunals are careful to protect non-party interests, they are also committed to fully discharging their duties vis-à-vis the parties before them by delimiting their entire maritime boundary or as much of the maritime boundary as has been requested. These two considerations create an obvious tension for the dispute settlement body, which must carefully balance the interests of the parties with the interests of non-party third states.

The following three subsections divide the "third-state" cases into three categories: ${ }^{58}$ (1) those in which the geographic limits of the delimitation were defined by the parties; (2) those in which the geographic limits of the

Report Number 4-9 at 2667.

Report Number 8-16 in this volume.

The North Sea Continental Shelf cases are not included because the Court was not asked to delimit specific boundaries, but only to provide the principles that should be used by the parties in their subsequent negotiations. It should be noted that in the North Sea cases the Court, in 
delimitation were not defined by the parties, but in which the third-state interests were known to the dispute settlement body; and (3) those in which the geographic limits were not defined, nor were third-state interests known. ${ }^{59}$ Where the parties have defined the outer geographic limits of the delimitation, the tripoint issues are much simplified. However, partydefined limits have not prevented dispute settlement bodies from questioning the appropriateness of those limits. Where third-state interests were known to the dispute settlement body, those interests generally have been respected ${ }^{60}$ Where third-state interests were not known, courts and tribunals appear to have limited the geographic scope of their decisions to within the equidistant line between the parties and the third state. In most cases, the dispute settlement body has been careful to point out that, in any event, the effect of its decision is only binding on the parties.

Each case synopsis below contains a brief description of the geographic context of the case, the third-state interests to the extent they were known, and the drafting technique used by the dispute settlement body to avoid prejudicing that third-state interest. In the two cases with clear, partydefined limits, the dispute settlement bodies created endpoints without explicit intent of future extension. ${ }^{61}$ However, in the cases in which the parties did not define the geographic scope of their requested delimitation, dispute settlement bodies have limited themselves to the two most ambiguous drafting techniques described in the previous section: (1) creating an endpoint on an azimuth, ${ }^{62}$ and (2) creating an endpoint without prejudice to future extension. ${ }^{63}$

\section{Party-Defined Limits}

\section{France/United Kingdom (Ireland) ${ }^{64}$}

In this arbitration the ad hoc Court of Arbitration was requested to delimit the continental shelf boundary "westward of 30 minutes west of the Greenwich

enumerating the relevant principles, referred to continental shelf delimitations, actual or prospective, with third states in the region. 1969 I.C.J. 31 (Feb. 20).

59 In two of the cases with two endpoints, Eritrea/Yemen and Qatar v. Bahrain, the endpoints are in different categories.

60 For an exception, see the tribunal's treatment of known Saudi Arabian interests in Eritrea/Yemen.

61 These cases include: France/United Kingdom; and Denmark v. Norway.

62 These cases include: Tunisia v. Libya; Qatar v. Bahrain; and Cameroon v. Nigeria.

63 These cases include: Libya v. Malta; and Eritrea/Yemen.

64 Report Number 9-3. 
Meridian as far as the 1,000 metre isobath." ${ }^{\prime 65}$ With this description the parties created clear geographic limits for the court. This description put any Belgian interest in the northeast well outside the scope of the court's consideration. However, Irish interests at the southwestern end of this boundary were potentially within the scope of the Court of Arbitration's mandate. No other delimitations existed in the vicinity of the southwestern limit at the time.

Although it does not appear from the record that Ireland submitted any information directly to the Court of Arbitration, Ireland's interests were generally known through the submission, by the parties, of diplomatic correspondence and other documents. ${ }^{66}$ What the Court of Arbitration knew of Ireland's interests concerned it enough to ask the parties about "the possibility of the continental shelf boundary between France and the United Kingdom meeting the boundary between the United Kingdom and the Republic of Ireland at a tripoint to the east of the 1,000-metre isobath," that is, within the geographic limit defined by the parties. ${ }^{67}$ The parties' replies apparently did not "negative altogether the possibility" of a France-IrelandUnited Kingdom tripoint within the area to be delimited.$^{68} \mathrm{In}$ an attempt to balance the competing interests of fully discharging its delimitation duties to the parties on the one hand, and protecting the interests of Ireland on the other, the Court of Arbitration made two relevant statements. First, that it was not "open to the Court ... to pronounce in these proceedings on the position of the tripoint." ${ }^{69}$ Second, that "[t]he Court's Decision ... will neither be binding upon nor create any rights or obligations for any third State, and in particular for the Republic of Ireland, for which this Decision will be res inter alios acta." 70

With these assurances the Court of Arbitration then proceeded to delimit the boundary as far as the 1,000 meter isobath. Point $\mathrm{N}$ of the decision, the final southwestern point, represents the intersection between the France-United Kingdom continental shelf boundary and the 1,000 meter

65 Arbitration on the Delimitation of the Continental Shelf (Fr./U.K.) 18 I.L.M. 397, 400 (1979) (June 30, 1977)

$66 I d$. at 411. The pleadings in this arbitration are not public, so information about the positions of the parties and information before the Court of Arbitration must be gleaned from the judgments and from reviews of the decision written by scholars with inside information.

67 Id. at 412.

68 Id.

$69 I d$.

70 Id. 
isobath. ${ }^{71}$ A decade after the decision in this case, Ireland and the United Kingdom concluded their continental shelf treaty in the Celtic Sea and into the Atlantic Ocean. ${ }^{72}$ That boundary passed to the west of point $\mathrm{N}$ leaving for future negotiations a potential France-Ireland-United Kingdom tripoint beyond the end of the line established by the Court of Arbitration.

\section{Denmark v. Norway (Iceland) ${ }^{73}$}

In this case the ICJ was asked to delimit the maritime boundary between Denmark's territory of Greenland and Norway's island of Jan Mayen. Iceland is located to the south within 400 n.m. of both parties and had already delimited most of its boundary with Norway (Jan Mayen) at the time of this case. Denmark, in its Memorial, defined the southern limit of the area to be delimited as the 200 n.m. limit from the nearest Icelandic territory. ${ }^{74}$ This represented Iceland's maximum claim and was designed to avoid prejudicing any Icelandic interests. The Court, in its judgment, adopted the Danish definition of the area to be delimited, writing "to the south it is limited by a line BCD on sketch-map No. 1 representing the limit of the 200-mile economic zone claimed by Iceland. Denmark requests the Court to limit its decision to the areas north of that line, a position which is accepted by Norway." 75

This case presented a unique situation in which the maximum claim of the third state was known to the parties and the Court, and that claim was used by the parties to define the outer limit of the Court's delimitation exercise.

Not surprisingly the Court defined the southern endpoint of its line, point M, as "on the 200-mile line claimed by Iceland."76 In a subsequent 1995 agreement between the parties, which "recorded the consent of the two governments to draw the boundary ... in accordance with the Court's judgment," point $\mathrm{M}$ was shifted very slightly and renamed point $4 .{ }^{77}$ The preamble to the 1995 agreement refers to the delimitation of the boundary

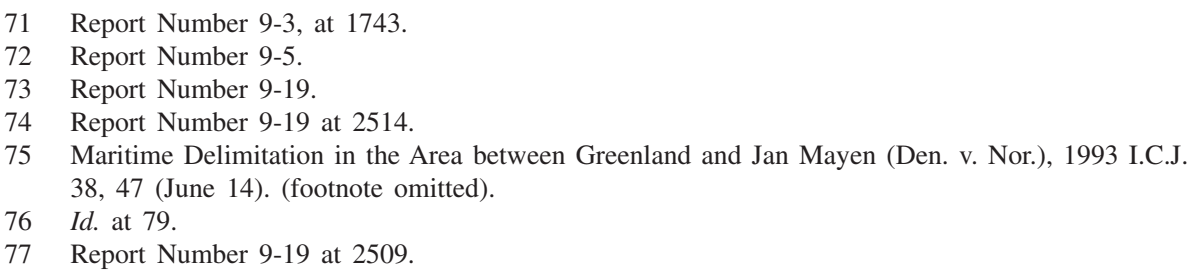


south of point 4 which "must be effected in consultation with Iceland." 78 In fact, two years later Denmark and Norway, having consulted Iceland, signed a protocol to their 1995 agreement, which defined point 5 - the purported Denmark-Iceland-Norway tripoint. ${ }^{79}$

\section{No Party-Defined Limits, Third-State Interests Known}

\section{Tunisia v. Libya (Malta) $)^{80}$ ○.}

In their Special Agreement the parties asked the ICJ what were "the principles and rules of international law which may be applied for the delimitation of the area of the continental shelf appertaining to [Tunisia] and the area of the continental shelf appertaining to [Libya]." ${ }^{81}$ The parties left it to the Court to determine the geographic limits of those areas vis-à-vis third states. ${ }^{82}$ Two third states were present in the vicinity of this delimitation - Italy and Malta. Italy had already defined its interests as against Tunisia in a maritime boundary agreement concluded several years earlier. ${ }^{83}$ That agreement ended at a point approximately equidistant from Malta and the mid-sea Italian islands of Linosa and Lampedusa. ${ }^{84}$ At the time of this case Italy had expressed no boundary interest as against Libya in this area. ${ }^{85}$ Apparently satisfied that its interests would not be endangered by the Court's delimitation, Italy did not attempt to express those

Report Number 9-19 at 2524.

Report Number 9-19(2) at 2919.

Report Number 8-9.

81 Continental Shelf (Tunis./Libya) 1982 I.C.J. 18, 21 (Feb. 24). Unlike the North Sea Continental Shelf cases in which the parties requested only the principles, the parties to this case went on to request the Court "to specify precisely the practical way in which the aforesaid principles and rules apply in this particular situation so as to enable the experts of the two countries to delimit those areas without any difficulty." Id.

82 In oral argument on Malta's application to intervene in Tunisia v. Libya, Malta's agent highlighted the problem the Court would face in defining the outer geographic limit of its jurisdiction solely on the basis of the language of the Special Agreement. The parties' argument "is to the effect that Malta's situation cannot be affected because the Libya/Tunisia proceedings are so conceived that any delimitation of the continental shelf boundary lines of those two States will be suspended at the point where it might impinge on those of other States in the region. Here I might ask... how will it be known when that point is reached without entering upon the question of Malta's continental shelf entitlement?" Oral Arguments on the Application by Malta for Permission to Intervene (Tunis./Libya), I.C.J. Pleadings (3 Continental Shelf) at 285 (Mar. 19, 1981).

83 Report Number 8-6.

84 Report Number 8-6 at 1612.

85 See Written Observations of Libya on Application by Italy for Permission to Intervene 
interests to the Court and, in fact, did not even request the pleadings in this case. ${ }^{86}$

Malta took a more proactive approach to protecting its interests by applying to intervene in the proceedings. Although Malta's attempt to intervene was ultimately unsuccessful, it did afford Malta the opportunity, through written and oral pleadings, to make the Court aware of the geographic extent of its interests. Malta defined its interests with an equidistant line between Malta and the three neighboring states: Tunisia, Libya and Italy (with the exception of Italy's mid-sea islands of Linosa and Lampedusa to which Malta gave only 12 n.m. belts). ${ }^{87}$ Upon denying Malta's application to intervene, the Court assured Malta that it understood Malta's "preoccupations... regarding possible implications for its own interests of the Court's findings." 88 Judge Oda went farther in his separate opinion, writing that "the legal interests of Malta... will be sufficiently safeguarded by this Court, the more so because Malta has by its argument brought its understandable preoccupations to the Court's attention." ${ }^{89}$

With Malta's interests in mind the Court turned to the tasks of identifying the principles and rules of delimitation to be used between the parties and specifying the way in which those principles and rules should be used to delimit a boundary. In the judgment the Court referred to "the rights of other States" in the area, ${ }^{90}$ and acknowledged that "the terminal point to seaward of the delimitation line ... cannot be determined with any precision by the Court" because of the presence of third states. ${ }^{91}$ In order to deal with this limitation, the Court defined the penultimate turning point, which was located well outside Malta's area of interest, and then provided an azimuth of $52^{\circ}$ from that point, specifying that "the extension of this line northeastwards is a matter falling outside the jurisdiction of the Court in the present case, as it will depend on the delimitation to be agreed with

(Libya/Malta), I.C.J. Pleadings (2 Continental Shelf) at 429 ("[T]he Application now made by Italy is the first occasion on which Italy has sought vis-à-vis Libya the establishment of claims to areas of continental shelf involving delimitation between their respective areas of continental shelf.").

86 See Oral Arguments on the Application by Malta for Permission to Intervene (Tunis./Libya), I.C.J. Pleadings (3 Continental Shelf) at 446 (Mar. 23, 1981).

87 See id. at 300 (Mar. 19, 1981). See also Oral Arguments on the Application by Malta for Permission to Intervene (Tunis./Libya), I.C.J. Pleadings (6 Continental Shelf) map 95 (1981).

88 Continental Shelf (Tunis./Libya), 1981 I.C.J. 3, 20 (April 14).

89 Id. at 23 (separate opinion of Judge Oda)

90 Continental Shelf (Tunis./Libya), 1982 I.C.J. 18, 62, 91 (Feb. 24).

$91 \quad I d$. at 82. 
third States." ${ }^{2}$ At the time of writing, the envisioned delimitation with third States has not yet occurred.

\section{Libya v. Malta (Italy) ${ }^{93}$ ?}

Only months after the ICJ delivered its judgment in Tunisia v. Libya, Libya and Malta submitted a Special Agreement requesting the Court to delimit their continental shelf boundary. Libya v. Malta was similar to Tunisia $v$. Libya in several respects. First, the geographic scope of the delimitation was left undefined by the parties. In this regard, the Special Agreement was nearly identical to that in Tunisia v. Libya requesting a "delimitation of the area of the continental shelf which appertains to [the parties]." Second, third states - Italy and Tunisia - were present in the vicinity of the requested delimitation. Third, Tunisia was apparently not concerned that its interests might be prejudiced, while Italy was concerned enough to attempt to intervene. Fourth, Italy's intervention attempt, while ultimately denied, gave Italy the opportunity to relate its interests to the Court.

During its intervention attempt Italy effectively conveyed to the Court its interests in the area to be delimited through extensive oral pleadings, ${ }^{95}$ a map, ${ }^{96}$ and a written response to a question by Judge de Lacharrière requesting more precise information about Italy's area of interest. ${ }^{97}$ In response to de Lacharrière's request, Italy provided the exact lines of longitude that defined the western limit of Italy's area of interest east of the area to be delimited $-15^{\circ} 10^{\prime} \mathrm{E}$ - and the eastern limit of Italy's area of interest west of the area to be delimited $-13^{\circ} 50^{\prime} \mathrm{E}$. The Court explicitly adopted Italy's limits as the outer limits of the delimitation..$^{98}$

Although the information available to the Court about third-state interests was qualitatively similar in Libya v. Malta and Tunisia v. Libya, that is, a well-defined maximum claim of the intervening states, the Court

92 Id. at $93-94$.

93 Report Number 8-8.

94 Continental Shelf (Libya/Malta), 1985 I.C.J. 13, 16 (June 3).

95 See generally Oral Arguments on the Application by Italy for Permission to Intervene (Libya/ Malta), I.C.J. Pleadings (2 Continental Shelf).

96 Id. (5 Continental Shelf) map 25.

97 Letter from Italy Responding to Judge de Lacharriere (Libya/Malta), I.C.J. Pleadings (4 Continental Shelf) at 506-07 (1984).

98 "The limits within which the Court, in order to preserve the rights of third States, will confine its decision in the present case, may thus be defined in terms of the claims of Italy." Continental Shelf (Libya/Malta), 1985 I.C.J. 13, 26 (June 3); See also id. map at 27. 
treated those interests differently in the two cases. While in Tunisia $v$. Libya the Court defined an endpoint on an azimuth, in Libya v. Malta the Court created endpoints precisely on the limits created by Italy's maximum claim and stopped its delimitation there. ${ }^{99}$ However, the Court did allude to a possible Libya-Malta boundary relationship beyond the Court's endpoints when it wrote, "no inference can be drawn from the fact that the Court has taken into account the existence of Italian claims." 100 This ambivalent endpoint approach appears to preserve for Libya and Malta the option of a future extension beyond the Court's endpoints.

\section{Eritrea/Yemen (Saudi Arabia) ${ }^{101}$}

In this two-stage case the parties requested an ad hoc tribunal first to decide questions of territorial sovereignty over several disputed islands in the Red Sea, and second to delimit the maritime boundary between the parties taking into account the first-stage sovereignty award. ${ }^{102}$ Although third-states were present at both ends of the delimitation area - Saudi Arabia in the north and Djibouti in the south - the Arbitration Agreement did not define the geographic limits of the delimitation area. To complicate matters, Saudi Arabia and Yemen were engaged in a sovereignty dispute over an island - Dhu Harab - which, if Saudi Arabia's, would be the nearest Saudi territory to the delimitation area. A latent sovereignty dispute between Eritrea and Djibouti over the islands of Dumeira and Callida may have caused similar problems for the tribunal at the southern end of the delimitation area. ${ }^{103}$

Saudi Arabia, in an effort to protect its interests wrote to the tribunal "suggesting that the Tribunal should restrict its decision to areas 'that do not extend north of the latitude of the most northern point on Jabal al Tayr island'." 104 This latitude is approximately $15^{\circ} 33^{\prime} 40^{\prime \prime} \mathrm{N}$. In response to Saudi Arabia's suggestion and the views of the parties as to outer limits of

\footnotetext{
99 Id. at $56-57$

$100 \quad$ Id. at 28.

101 Report Number 6-14

102 Arbitration Agreement (Eri./Yemen), 40 I.L.M. 983, 1014 (2001) (Oct. 3, 1996).

103 The written and oral pleadings of the Eritrea/Yemen arbitration are still confidential as per Art. 9.3 of the Arbitration Agreement, so it is difficult to know of what the tribunal was made aware. See Chris M. Carleton, Region VII Report, infra (referring to potential sovereignty dispute between Djibouti and Eritrea).

104 Second Stage of the Proceedings (Maritime Delimitation) (Eri./Yemen), 40 ILM 983, 990 (2001), (Dec. 17, 1999) [hereinafter Eritrea/Yemen].
} 
the delimitation area, the tribunal stated that it "[had] taken into consideration these positions variously expressed and [had] reached its own conclusions." ${ }^{05}$ Apparently the tribunal concluded that Saudi Arabia's suggestion was too protective and instead delimited the northern endpoint, point 1 , approximately 10 n.m. north of and beyond the suggested latitude. ${ }^{106}$

In establishing the location of the northern endpoint the tribunal believed that it was "well short of where the boundary line might be disputed by any third State." ${ }^{107}$ Few materials from the arbitration are publicly available, so it is difficult to know how the tribunal arrived at point $1 .{ }^{108}$ It is also not clear why the tribunal was so confident about the nonprejudicial location of point 1 in light of the Saudi letter. However, hindsight indicates that the tribunal was correct. Six months later Saudi Arabia and Yemen concluded a maritime boundary agreement which resolved the Dhu Harab sovereignty dispute in Yemen's favor and created a maritime boundary well north of point $1 .{ }^{109}$

\section{Qatar v. Bahrain (Iran) ${ }^{110}$ ○.}

In this case Qatar requested that the ICJ "draw in accordance with international law a single maritime boundary between the maritime areas of sea-bed, subsoil and superjacent waters appertaining respectively to the State of Qatar and the State of Bahrain." 111 The parties did not define the outer limits of the delimitation area even though third states were present at both ends - Iran in the north and Saudi Arabia in the south.

Iranian interests in the north were already defined by a pair of agreements - Bahrain-Iran and Iran-Qatar - that were concluded two decades

$105 I d$.

106 For starkly contrasting treatments of third-state interests, compare the tribunal's response to Saudi Arabia's suggestion in Eritrea/Yemen with the Court's response to Italy's claims in Libya v. Malta.

107 Id. at 1010. This was an odd conclusion considering that point 1 was far north of the limit requested by Saudi Arabia.

108 Based on language in the Arbitration Award at paragraph 136 and some cursory geographic analysis, this author suspects that the tribunal first constructed a median line using basepoints that included the disputed features at either end of the delimitation area, but then stopped the boundary at the first turning point influenced by a disputed feature. See id. at 1006. This theory is born out for point 1 which is equidistant from a small Dahlak islet (Eritrea), Kutama Island (Yemen), and Dhu Harab (Saudi Arabia/Yemen).

109 See Report Number 6-16.

110 Report Number 7-13.

111 Maritime Delimitation and Territorial Questions (Qatar v. Bahr.), 2001 I.C.J. 40, 49 (Mar. 16) [hereinafter Qatar v. Bahrain]. 
before Qatar brought this case. ${ }^{112}$ Therefore it was not necessary for Iran to present its position, as it was already well known. Read together, these agreements defined the maximum Iranian claim as against Bahrain and Qatar, although the agreements left open where along the boundary with Iran the interests of Bahrain would end and the interests of Qatar would begin.

The Court delimited a boundary based primarily on equidistance. In order to deal with the presence of Iran, the Court defined a penultimate northern turning point, point 42 , and then provided an azimuth to continue the boundary beyond point 42 . Specifically, the Court wrote: "Beyond point 42 , the single maritime boundary shall follow, in a north-north-easterly direction, a loxodrome having an azimuth of $12^{\circ} 15^{\prime} 12^{\prime \prime}$, until it meets the delimitation line between the respective maritime zones of Iran on the one hand and of Bahrain and Qatar on the other." ${ }^{113}$ The Court's azimuth solution combined with the two preceding bilateral agreements, leaves only minor technical issues to be resolved by the parties if they choose to conclude a trilateral tripoint agreement.

\section{Cameroon v. Nigeria (Equatorial Guinea) ${ }^{114}$ \...}

In this case Cameroon requested the ICJ to "determine the course of the maritime boundary between the two States." 115 Equatorial Guinea's Bioko Island is located approximately 40 n.m. south of the disputed Bakassi Peninsula and the starting point of the maritime boundary. Nigeria's maritime boundary position was based on equidistance starting east of the Bakassi Peninsula and continuing toward an equidistant tripoint among the parties and Equatorial Guinea. The Nigerian position complemented to some degree Nigeria's previously delimited boundary with Equatorial Guinea. ${ }^{116}$ Cameroon's maritime boundary position against Nigeria started on the west side of the Bakassi Peninsula, cut between the coasts of Equatorial Guinea and Nigeria, and continued out to sea to a distance of approximately 230 n.m. from the nearest point on the coast of Cameroon. ${ }^{117}$ By discounting,

112 Report Numbers 7-2, 7-6; see discussion supra Part II.B.3.

113 Qatar v. Bahrain, supra note 111 , at 116

114 Report Number 4-1(Add. 2).

115 Land and Maritime Boundary (Cameroon v. Nig.: Eq. Guinea intervening), 2002 I.C.J. 303, 312 (Oct. 10) [hereinafter Cameroon v. Nigeria].

116 See Report Number 4-9.

117 Rejoinder of Nigeria (Cameroon v. Nigeria: Equatorial Guinea intervening), at para. 12.23 
or entirely disregarding, the presence of Equatorial Guinea, Cameroon's position stood in stark contrast to the coastal geographic realities in the area. Cameroon's position also implied the absence of two features in the political geographic landscape that were based on long-standing diplomatic and oil concession practice among the three states: (1) an Equatorial Guinea-Nigeria maritime boundary relationship, and (2) a CameroonEquatorial Guinea-Nigeria tripoint relationship.

In order to protect its interests, Equatorial Guinea applied to intervene in this case. For the first time in international maritime boundary dispute settlement, the Court allowed the intervention. This gave Equatorial Guinea the unique opportunity to make its interests known to the Court not only through the intervention proceedings, as had Malta and Italy before it, but also as a non-party intervenor in subsequent stages of the case. Throughout the process Equatorial Guinea maintained that since it was not a party to the case before the Court, the Court should not establish a NigeriaCameroon maritime boundary that fell within Equatorial Guinea's equidistance line claim.

The Court, in formulating its maritime boundary judgment between Cameroon and Nigeria, relied in the nearshore area on previous boundary agreements between the parties. Further offshore, where these previous boundaries terminated, the Court continued the boundary on the basis of equidistance. In order to deal with Equatorial Guinea's interests at the southern end of the Cameroon-Nigeria boundary, the Court used the familiar azimuth technique. The Court wrote: "In these circumstances the Court considers that it can do no more than indicate a general direction, from point X, of the boundary between the Parties' maritime areas. The boundary will follow a loxodrome having an azimuth of $187^{\circ} 52^{\prime} 27^{\prime \prime} . " 118$ The Court added, "this equidistance line cannot be extended beyond a point where it might affect rights of Equatorial Guinea." 119

(January 2001) available at http://www.icj-cij.org/icjwww/idocket/icn/icnframe.htm (last visited Oct. 27, 2004).

118 Cameroon v. Nigeria, supra note 115 , at 448 .

$119 I d$. at 443. 
3 No Party-Defined Limits, Third-State Interests Unknown

$$
\text { Eritrea/Yemen (Djibouti) })^{120}
$$

The geographic context of the southern end of this boundary delimitation is described above in the section that covers Saudi Arabia's interests in the north. The main difference between the two endpoints is that in the south Djibouti did not make its interests known to the tribunal. ${ }^{121}$ As with the northern endpoint, the tribunal concluded that the southern endpoint, point 29 , was "well short of where the boundary line might be disputed by any third State." 122 Djibouti and Eritrea have yet to conclude their lateral maritime boundary which could confirm or conflict with the tribunal's assertion.

\section{Qatar v. Bahrain (Saudi Arabia) ${ }^{123}$ \..}

As stated above, the ICJ had to deal with the presence of Saudi Arabian territory at the southern end of this boundary. However, unlike Iranian interests in the north, which were clearly defined by two preceding boundary agreements, Saudi Arabia's interests in the south were not known to the Court. The only boundary agreement in the vicinity of the southern end of the Qatar-Bahrain delimitation area was the Bahrain-Saudi Arabia boundary which appears to be only partially delimited. There is no indication in the record that Saudi Arabia made its position known to the Court during the proceedings between Bahrain and Qatar. In the absence of defined Saudi Arabian interests in this area, the Court appears to have limited the delimitation to the area within an equidistant line between the parties and Saudi Arabia. In order to do this, the Court defined a penultimate turning point that was closer to the coasts of the parties than to Saudi Arabia, and then provided an azimuth from that turning point to take the boundary toward the third state. The Court wrote: "Below point 1, the single maritime boundary shall follow, in a south-westerly direction, a loxodrome having an azimuth of $234^{\circ} 16^{\prime} 5^{\prime \prime}$, until it meets the delimitation line between the respective maritime zones of Saudi Arabia on the one hand and of Bahrain and Qatar on the other." 124

\footnotetext{
120 Report Number 6-14.

121 Eritrea/Yemen, supra note 104, at 990.

122 Id. at 1010

123 Report Number 7-13.

124 Qatar v. Bahrain, supra note 111, at 116.
} 


\section{Boundary Cases Currently Pending}

At the time of this writing, three maritime boundary cases are on the ICJ docket - Nicaragua v. Honduras, ${ }^{125}$ Nicaragua v. Colombia ${ }^{126}$ and Romania v. Ukraine ${ }^{127}$ - all of which contain tripoint issues. There is a tripoint issue in Nicaragua v. Honduras, but with which third state, Colombia or Jamaica, will depend in part on the location of the Court's line. In Nicaragua v. Colombia, if the case proceeds to the merits, the Court will probably be faced with more than one tripoint issue. Depending upon the outcome of the island sovereignty question in that case and the direction and location of the Court's line, the interests of Costa Rica, Honduras, Jamaica and Panama could be involved. The outcome in Nicaragua v. Colombia could also have the effect of eliminating existing trilateral geographic relationships and their associated tripoints. ${ }^{128}$ There will be a tripoint issue at the seaward end of the delimitation in Romania v. Ukraine. It will most likely be with Turkey, but Bulgaria is also in the vicinity.

Also at the time of this writing, three UNCLOS Annex VII arbitration tribunals have been formed to decide maritime boundary questions: Malaysia/Singapore (in part), Barbados/Trinidad and Tobago ${ }^{129}$ and Guyana/Suriname. ${ }^{130}$ It is possible that tripoint issues will arise in the case between Malaysia and Singapore. Malaysia, in its notification and statement of claim, requested the arbitral tribunal, among other things, "to delimit the boundary between the territorial waters of the two States in the area beyond Points W25 and E47 of the 1995 Agreement." ${ }^{131}$ Delimitations based on a broad interpretation of "between the territorial waters" would quickly approach Indonesia's interests at both ends of the Johor Strait, but would remain well short of the sovereignty dispute between Malaysia and Singapore over Pedra Branca/Pulau Batu Puteh, which is currently before the ICJ.

In Barbados/Trinidad and Tobago, if Barbados requests a complete delimitation, tripoint issues will arise at both ends of the Barbados-

\footnotetext{
125 Report Number 2-24.

126 Report Number 2-25.

127 Report Number 8-17.

128 See Report Numbers 2-1, 2-4, 2-5, 2-18.

129 Report Number 2-26.

130 Report Number 3-10.

131 Land Reclamation by Singapore in and around the Straits of Johor/ Request for Provisional Measures (Malay. v. Sing.), ITLOS Case No. 12 (Order of Oct. 8, 2003) at 7. Available at http://www.itlos.org (last visited Oct. 27, 2003).
} 
Trinidad and Tobago boundary. The western endpoint will probably involve St. Vincent and the Grenadines, and the eastern endpoint either Venezuela or Guyana. In the east, the tribunal will also be faced with two existing maritime delimitations, which are themselves in direct conflict - Trinidad and Tobago-Venezuela and Barbados-Guyana. ${ }^{132}$

In order to determine the geographic scope of the delimitation in Guyana/Suriname one must consider the long-standing sovereignty dispute between Guyana and Venezuela over the Essequibo region. The tribunal will not be asked to decide this issue, but the ongoing dispute has a direct impact on potential tripoint issues. If the disputed region, and its coastline, is Venezuela's, Guyana, Suriname and Venezuela would have a coastal geographic relationship that indicates a potential tripoint within 200 n.m. of their coasts. If the disputed region is Guyana's, a potential tripoint would not arise until much farther out to sea, if at all.

\section{THE TRILATERAL PERSPECTIVE}

The purpose of the trilateral perspective is to understand the status and estimate the location of tripoints on the basis of information provided by the coastal geography and the delimitation behavior of the relevant states. A tripoint can be either an actual tripoint, that is a delimited and agreed tripoint, or a potential tripoint, that is a geographically possible but not yet trilaterally agreed tripoint. A potential tripoint remains a purely theoretical entity until it is turned into an actual tripoint through a trilateral agreement among, and binding on, all three parties. At the time of this writing, only eight such agreements exist. ${ }^{133}$ With those exceptions all other tripoints discussed in this report are merely potential tripoints.

In order to analyze and classify their trilateral aspects, this study uses a five-tiered ranking system based on the certainty and location of the 127 actual and potential tripoints indicated by agreements reported in Volumes $\mathrm{I}-\mathrm{V}$ of this series. Each of these tripoints has been assigned a rank in light of existing bilateral and trilateral agreements. The results are found in the accompanying table. The most certain category is actual tripoints. The four remaining categories are of potential tripoints in descending order of certainty: presumed tripoints, probable tripoints, uncertain tripoints, and conflict-

132 Report Numbers 2-13, 2-27.

133 See supra note 19. 
ing tripoints. In Sections A through E below each category is described. As with the delimitation techniques described in this paper, a stylized symbol is used to represent each category. ${ }^{134}$ Section $\mathrm{F}$ addresses briefly the role of joint zones in tripoint creation and analysis.

\section{A Actual Tripoint $\bullet$}

Actual tripoints are tripoints that have been defined and agreed in a trilateral treaty. These are the most certain of tripoints but are fairly uncommon. Only eight have been completed at the time of this writing: four in the eastern Indian Ocean, three in the Baltic Sea, and one in the Caspian Sea. Of these tripoint agreements, five were concluded only after, or simultaneously with, the conclusion of the three associated bilateral agreements. ${ }^{135}$ The other three tripoint agreements were concluded before all three bilateral agreements had been concluded. ${ }^{136}$

Some tripoint agreements delimit both the tripoint itself and the final segments of one or more of the associated bilateral agreements. ${ }^{137}$ The language in Article 1 of the Poland-Sweden-Soviet Union treaty is typical of this type of tripoint agreement. It states: "From the points indicated below [providing the endpoint names and coordinates of the three preceding bilateral agreements] the delimitation line continues along straight lines (geodetic lines) to the junction point." ${ }^{138}$ Other tripoint agreements delimit only

134 These symbols appear in the accompanying table and should give the user a visual cue for quickly identifying tripoints within a certain category.

135 Report Numbers 6-7 (India-Indonesia-Thailand), 6-11 (Add. 1) (India-Myanmar (Burma)Thailand), 10-12 (Poland-Russia-Sweden), 10-21 (Estonia-Finland-Sweden), 11-4 (AzerbaijanKazakhstan-Russia).

136 The India-Maldives-Sri Lanka, India-Malaysia-Thailand, and the Estonia-Latvia-Sweden tripoint agreements are examples of agreements reached before all three bilateral agreements were concluded. Report Numbers 6-9, 6-12, 10-17. In fact, the India-Maldives-Sri Lanka tripoint agreement was concluded with only the India-Sri Lanka boundary agreement in place. Maldives and Sri Lanka have yet to conclude their maritime boundary nearly thirty years after the tripoint agreement was signed. Report Numbers 6-8, 6-9, 6-10(2). The Estonia-Latvia-Sweden tripoint agreement was concluded after only the Estonia-Latvia agreement had been concluded. The bilateral agreement between Estonia and Sweden was concluded about eighteen months after the tripoint agreement, and Latvia and Sweden have not yet delimited their boundary. Report Numbers 10-15, 10-17, 10-19.

137 For example, the Indonesia-Malaysia-Thailand tripoint agreement creates final segments radiating from the tripoint out to, or at least toward in the case of the Malaysia-Thailand boundary, the endpoints on previously delimited bilateral boundaries. Report Numbers 5-9, 5-13(1), 6-12, 6-13. The other tripoint agreements that use this technique are India-Indonesia-Thailand, EstoniaFinland-Sweden, Estonia-Latvia-Sweden, Poland-Russia-Sweden.

138 Report Number 10-12 at 2103-04. 
the tripoint and, where necessary, leave the parties to extend their boundaries to the tripoint in future bilateral delimitations. ${ }^{139}$ Article 1 of the India-Maldives-Sri Lanka treaty provides an example of this type of agreement. It states: "The tri-junction point ... shall be the point . . . defined by latitude and longitude as follows." 140

\section{B Presumed Tripoint ••}

In a slightly larger category are presumed tripoints. This study has identified 14 presumed tripoints. Some presumed tripoints consist of three coincident endpoints in the three associated bilateral treaties. Despite apparent agreement, these are still only presumed tripoints because they lack a trilateral agreement to tie them together. ${ }^{141}$ Other presumed tripoints are formed by three nearly coincident endpoints - endpoints that would be precisely coincident but for minor discrepancies in the horizontal datums or endpoint coordinates among the triplet of bilateral agreements. ${ }^{142}$ Despite these minor discrepancies, it is fairly clear that in these situations the parties intended to create coincident endpoints. ${ }^{143}$

Included in this category are those tripoints that are formed descriptively rather than with endpoint coordinates, but which lead to only one possible location for the potential tripoint. The two Colombia-Costa RicaPanama tripoints are examples of this type of presumed tripoint. In the Caribbean the first of the three associated bilateral agreements, between

139 Report Numbers 6-9 (India-Maldives-Sri Lanka), 6-11(Add. 1) (India-Myanmar (Burma)Thailand), 11-4 (Azerbaijan-Kazakhstan-Russia).

140 Report Number 6-9 at 1407.

141 The potential tripoint among Denmark (Greenland), Iceland and Norway (Jan Mayen), represents an extreme example of a tripoint that remains merely a presumed tripoint despite obvious agreement among the three states as to its status and location. Here, the three relevant bilateral agreements were signed on the same date, in the same place, and as a result of trilateral consultations; each identifies the same point as the tripoint; each identifies the third state in the text of the agreement; and each makes entry into force of the bilateral agreement contingent on notification by the third state that the determination of the tripoint has been confirmed. However, no trilateral agreement exists among the three states. Report Numbers 9-4(2), 9-19(2), 9-22.

142 For example, Australia-France (New Caledonia) point R1 and Australia-Solomon Islands point R1 are both referenced to WGS 72. This same point referenced to WGS 84 has coordinates $15^{\circ}$ $44^{\prime} 06.8633^{\prime \prime} \mathrm{S}, 158^{\circ} 45^{\prime} 39.5540^{\prime \prime}$ E. This is approximately 17 meters northeast of France (New Caledonia)-Solomon Islands point 23 at $15^{\circ} 44^{\prime} 07^{\prime \prime} \mathrm{S}, 158^{\circ} 45^{\prime} 39^{\prime \prime} \mathrm{E}$ which is referenced to WGS 84. Report Numbers 5-1, 5-4, 5-17.

143 For this study 100 meters was chosen as the arbitrary cut off between nearly coincident and not coincident. Endpoints that are more than 100 meters apart are not considered to be coincident. See, for example the endpoints of the Cape Verde-Senegal and Cape Verde-Mauritania agreements, which are approximately 150 meters apart. Report Numbers 4-8(Vol. III), 4-12. 
Colombia and Panama, described the final segment of the boundary as "[f]rom Point $\mathrm{M}\left[11^{\circ} 00^{\prime} 00^{\prime \prime} \mathrm{N}, 81^{\circ} 15^{\prime} 00^{\prime \prime} \mathrm{W}\right]$, the delimitation continues along a straight line by azimuth 225 ( $45^{\circ}$ southwest) until a point where the maritime limits with a third State should be made." ${ }^{144}$ The next associated boundary, between Colombia and Costa Rica, used a similar description and added the latitude at which the Colombia-Panama boundary would meet the Colombia-Costa Rica boundary. ${ }^{145}$ The third boundary of the triplet, between Costa Rica and Panama, then identified the coordinates of the presumed tripoint and described it as "where the boundaries of Costa Rica, Colombia, and Panama intersect." 146 A similar set of boundaries defined the Colombia-Costa Rica-Panama tripoint in the Pacific Ocean. ${ }^{147}$

The Bahrain-Iran-Qatar tripoint represents yet another version of a presumed tripoint. When combined, the Bahrain-Iran boundary and the IranQatar boundary created a line segment along which the tripoint must be located. ${ }^{148}$ The Court's decision in Qatar v. Bahrain, without defining the tripoint in terms of coordinates, provided enough information (the coordinates of the penultimate turning point and an azimuth) to locate the presumed tripoint along the previously defined line segment. ${ }^{149}$ Despite the fact that none of the three bilateral boundaries provides the coordinates of its endpoint, the Bahrain-Iran-Qatar tripoint is a presumed tripoint because identifying the coordinates "should be no more than a technical exercise."150

\section{Probable Tripoint}

Probable tripoints are those for which two of three boundaries have been completed and contain either precisely coincident endpoints, ${ }^{151}$ nearly coincident endpoints, ${ }^{152}$ or are described in a way that could lead to only one

144 Report Number 2-5 at 533.

145 " $[\mathrm{T}]$ he intersection of a straight line, drawn with azimuth $225^{\circ}\left(45^{\circ} \mathrm{SW}\right)$ from $\left[11^{\circ} 00^{\prime} 00^{\prime} \mathrm{N}\right.$, $\left.81^{\circ} 15^{\prime} 00^{\prime \prime} \mathrm{W}\right]$, with the parallel $10^{\circ} 49^{\prime} 00^{\prime \prime}$ N." Report Number 2-1 at 474.

146 The coordinates of the presumed tripoint are $10^{\circ} 49^{\prime} 00^{\prime \prime} \mathrm{N}, 81^{\circ} 26^{\prime} 08.2^{\prime \prime} \mathrm{W}$. Report Number 2-6 at 548 .

147 See Report Numbers 2-5, 2-6, 3-6 (Add. 1, Corr. 1).

148 Report Numbers 7-2, 7-6.

149 Report Number 7-13.

150 Carleton, supra note 103 , in this volume.

151 The Colombia-Dominican Republic-Haiti tripoint is an example of precisely coincident endpoints. The Colombia-Dominican Republic boundary and the Colombia-Haiti boundary both contain endpoints located at $15^{\circ} 02^{\prime} 00^{\prime \prime} \mathrm{N}, 7^{\circ} 27^{\prime} 30^{\prime \prime}$ W. Report Numbers 2-2, 2-3.

152 The Cuba-Haiti-Jamaica tripoint is an example of nearly coincident endpoints. The Cuba-Haiti endpoint is $18^{\circ} 49^{\prime} 55.74^{\prime \prime} \mathrm{N}, 75^{\circ} 30^{\prime} 23.50^{\prime \prime} \mathrm{W}$, while the Cuba-Jamaica endpoint is $18^{\circ} 49^{\prime} 56^{\prime \prime}$ 
tripoint location. ${ }^{153}$ This study identifies 15 probable tripoints. These potential tripoints at least indicate agreement between two of the three states involved. Once the third agreement is completed, one of four things is likely to happen to the probable tripoint. First, the third agreement could provide an endpoint that is coincident with the endpoints of the previous two agreements. This would elevate the probable tripoint to a presumed tripoint. Second, the third agreement could fall short of the previous agreements. The probable tripoint would then remain a probable tripoint until further delimitation activity. Third, the third agreement could overstep one or both of the previous two agreements. This would downgrade the probable tripoint to a conflicting tripoint. Or, fourth, the third agreement could end on one of the two previously defined bilateral boundaries, but not at the location of the coincident endpoints. This would have the effect of shifting the potential tripoint location along a previously agreed line but without overstepping it and without creating a conflicting tripoint. This third possibility would also elevate the newly located potential tripoint to a presumed tripoint. ${ }^{154}$

\section{Uncertain Tripoint ::}

This is the largest category of potential tripoints. This study identifies 86 uncertain tripoints. Uncertain tripoints include those for which only one of three boundaries has been completed. In these single boundary situations little information is available about the position of the third state with regard to the endpoint of the single completed boundary. Uncertain tripoints also include those for which two or even all three associated bilateral boundaries have been completed, but completed so that all of them fall short of each other. Although this narrows the area in which the tripoint is likely to fall, it leaves the outside observer with limited information as to the final location of the potential tripoint within that area.

$\mathrm{N}, 75^{\circ} 30^{\prime} 23^{\prime \prime} \mathrm{W}$. Assuming both endpoints are referenced to the same datum, they would be less than 17 meters apart. Report Numbers 2-7, 2-19.

153 The Dominica-France (Guadelope)-Venezuela (Aves) tripoint is an example. The boundary between France and Venezuela is only defined as the meridian $62^{\circ} 48^{\prime} 50^{\prime \prime} \mathrm{W}$ without specified endpoints, and the endpoint of the Dominica-France boundary incorporates that meridian in its coordinates: $15^{\circ} 03^{\prime} 54^{\prime \prime} \mathrm{N}, 62^{\circ} 48^{\prime} 50^{\prime \prime} \mathrm{W}$. Report Numbers 2-11, 2-15.

154 See, for example, the Belgium-Netherlands-United Kingdom tripoint. The first two agreements - Netherlands-United Kingdom and Belgium-United Kingdom - shared coincident endpoints at $51^{\circ} 48^{\prime} 18^{\prime \prime} \mathrm{N}, 02^{\circ} 28^{\prime} 54^{\prime \prime}$ E. Report Numbers 9-13, 9-17. However, the third boundary in the 
As with probable tripoints, subsequent delimitations can impact the status of uncertain tripoints. A second delimitation in the vicinity of an uncertain tripoint could create a coincident endpoint and elevate the tripoint to a probable tripoint. It could overstep the first delimitation and downgrade the uncertain tripoint to a conflicting tripoint. The second delimitation could also create an endpoint that falls on the first boundary, but not at the original endpoint. This would have the double effect of shifting the potential tripoint along the first boundary and of elevating its status to a probable tripoint. ${ }^{155}$

\section{E Conflicting Tripoint :̊:}

The conflicting tripoint category is, surprisingly, the smallest of the five. ${ }^{156}$ There appear to be only five conflicting tripoints. Conflicting tripoints arise in trilateral geographic relationships in which two or three of the associated bilateral agreements have been concluded and in which the endpoints of at least two of the agreements overstep each other. This is the current situation among Equatorial Guinea (Rio Muni), Gabon and Sao Tome and Principe. Sao Tome and Principe has delimited boundaries with both Equatorial Guinea and Gabon, but has done so in a way that creates overstepping endpoints. The Gabon-Sao Tome and Principe endpoint is approximately seven n.m. north of and beyond the Equatorial Guinea-Sao Tome and

triplet - Belgium-Netherlands - ended at 51 $52^{\prime} 34.012^{\prime \prime} \mathrm{N}, 02^{\circ} 32^{\prime} 21.599^{\prime \prime}$ E. Report Number 9-21. The endpoint of the third agreement is located on the Netherlands-United Kingdom boundary and is the presumed tripoint among the three states.

155 This scenario unfolded during the boundary negotiations between Equatorial Guinea and Nigeria. Equatorial Guinea and Sao Tome and Principe had already agreed to a boundary with an endpoint designated as point 15 . The negotiations between Equatorial Guinea and Nigeria resulted in a boundary with an endpoint (point $\mathrm{x}$ ) that is not coincident with point 15, but which does fall on the previously agreed boundary with Sao Tome and Principe. Therefore the potential Equatorial Guinea-Nigeria-Sao Tome and Principe tripoint shifted from an uncertain tripoint at point 15 to a probable tripoint at point $x$. Report Numbers 4-8 (Vol. IV), 4-9.

156 The accompanying table addresses only tripoints that are actively in dispute as manifested by conflicting delimited maritime boundaries. Certainly there are many more latent disputed tripoints that have not made the list because they do not have associated overstepping agreements. The sovereignty and maritime boundary dispute between Colombia and Nicaragua is just one example of a situation in which there are several latently disputed tripoints. Both Colombia and Nicaragua claim sovereignty over islands that were the territorial basis for several of Colombia's maritime boundaries and their associated potential tripoints. Therefore, the sovereignty dispute between Colombia and Nicaragua indicates a latent dispute over the Colombia-HondurasNicaragua, Colombia-Honduras-Jamaica, Colombia-Costa Rica-Panama, and Colombia-Costa Rica-Nicaragua tripoints. 
Principe endpoint. ${ }^{157}$ A similar situation has been created among Colombia, Haiti and Jamaica, ${ }^{158}$ and among the Dominican Republic, the United States (Puerto Rico) and Venezuela. ${ }^{159}$ In order for this to occur, one of the three states must agree to a boundary with one neighbor that conflicts with a boundary already delimited with another neighbor. There is either an element of bad faith or lack of attention to detail in this practice. It may be that there are so few conflicting tripoints because states are generally reluctant to engage in inconsistent boundary delimitation behavior vis-à-vis their neighbors.

Conflicting tripoints also arise in quadrilateral geographic configurations. For example, the Trinidad and Tobago-Venezuela boundary, which appears to presume no tripoint relationship with either of the nearest coastal states, Barbados to the north and Guyana to the south, is clearly in conflict with the Barbados-Guyana Co-operation Zone agreement, which appears to presume no Venezuelan presence in that zone. ${ }^{160}$

\section{F Tripoints and Joint Zones Z}

The presence of a joint zone in the vicinity of a potential tripoint can further confuse an already uncertain situation. Because a joint zone creates an area between two of the three relevant states, instead of a line, joint zones obscure tripoint relationships without contributing much useful information about endpoints. Nonetheless, joint zones are part of the tripoint picture and merit some discussion here if only to clarify how they are approached in the accompanying table.

Of the joint zones in the world, nine are associated with potential tripoints. ${ }^{161}$ Only two of these zones are part of a larger boundary agreement, ${ }^{162}$ while the other seven occur in the absence of any maritime boundary between the parties to the joint zone. However, with or without an accompanying boundary, a joint zone indicates the existence of one of the three bilateral boundary relationships required to create a potential tri-

157 Report Numbers 4-8, 4-11.

158 Report Numbers 2-3, 2-18.

159 Report Numbers 2-9, 2-14.

160 Report Numbers 2-13, 2-27.

161 Report Numbers 2-18 (Colombia-Jamaica), 2-27 (Barbados-Guyana), 4-11 (Nigeria-Sao Tome and Principe), 5-12 (Japan-South Korea), 5-13 (Malaysia-Thailand), 5-19 (Malaysia-Vietnam), 5-21 (Cambodia-Vietnam), 5-24 (Cambodia-Thailand), 6-15 (Australia-East Timor),

162 Report Numbers 2-18 (Colombia-Jamaica), 5-12 (Japan-South Korea). 
point and serves as a placeholder for a possible future boundary. Therefore, joint zones are included in the accompanying table.

Joint zones do not have identifiable endpoints, and are therefore of relatively little assistance in identifying tripoint locations or understanding tripoint status. For that reason, the presence of joint zones was disregarded when determining the appropriate tripoint classification for potential tripoints with associated joint zones. Instead, with two exceptions, only the tripoint information available from the non-zone boundary agreements associated with each tripoint was considered. The first exception was for the China-Japan-South Korea tripoint which was included in the table solely on the basis of the Japan-South Korea Joint Development Zone. The second exception was for the potential "tripoint" among Barbados, Guyana, Trinidad and Tobago, and Venezuela, which is classified as a conflicting tripoint on the basis of the relationship between the Trinidad and TobagoVenezuela boundary and the Barbados-Guyana Cooperation Zone.

Of the potential tripoints with associated joint zones, one is a conflicting tripoint, seven are uncertain tripoints, and one is a probable tripoint.

\section{CONCLUSION}

Tripoints are like glue - while they can provide the adhesive to cement three separate bilateral agreements together, they can also make things very sticky. Tripoint issues make things sticky for parties to bilateral boundary negotiations - so sticky that the parties are often unable to delimit the entire length of their boundary until the third state is brought in through associated bilateral agreements or through a trilateral agreement. Tripoint issues also make things sticky for judges and arbitrators faced with the presence of a third state in the vicinity of the requested delimitation - a stickiness created by the tension between the court's "duty to decide the whole of the petitum entrusted to it; that is, to indicate the line of the frontier between the Parties over the entire length of the disputed area," ${ }^{163}$ and the court's reluctance to prejudice the interests of non-party, third states.

As discussed in the body of this report, there are various ways around sticky tripoint issues. An increasingly popular approach, especially among dispute settlement bodies, is to define the penultimate turning point and an

163 Frontier Dispute (Burk. Faso/Mali) 1986 I.C.J. 554, 579 (Dec. 22). 
azimuth from that point toward the third state. Another is to define an endpoint, recognizing that further, probably trilateral, negotiations will be required to continue beyond that point toward a tripoint. Yet another is to define an endpoint recognizing that its location may recede as a result of future negotiations.

Ultimately, tripoint issues will arise for the majority of states with undelimited or incompletely delimited maritime boundaries. As such, states and dispute settlement bodies will continue to address tripoint issues, and the state practice and jurisprudence of tripoints will continue to grow. There are many presumed tripoints that are ripe for a trilateral agreement to tidy up the boundary relationships. There are also many probable tripoints waiting for the third boundary in their triplet to come along and clarify matters. While progress towards clarity is made on these fronts, latent tripoint disputes will undoubtedly become overt and probable tripoints will be foiled by overstepping. We can hope that the net result will be a move toward clarity and peaceful resolution of undelimited maritime boundaries and their associated tripoints.

\section{EXPLANATORY LIST OF TERMS USED IN THE TABLE}

Rank The status (actual, presumed, probable, uncertain and conflicting) of each tripoint is indicated by the symbol in the "rank" column. A detailed description of each status level is provided in the body of this report. Every attempt has been made to apply the ranking system consistently across the 127 actual and potential tripoints considered in this table.

Actual or Potential Tripoint The names of the three states involved in an actual or potential tripoint related to one or more of the bilateral boundary agreements reported in Volumes I-V of this series are provided in the "actual or potential tripoint" column. The tripoints are alphabetized within each of the eleven regions. Where a specific part of a state's territory is responsible for creating the tripoint relationship, the name of that territory is given in parentheses. ${ }^{164}$ Where it is not clear with which third state a

164 See, for example, France (Martinique)-St. Lucia-Venezuela (Aves). Where three states have multiple tripoint relationships, north, south, east and west have been used to distinguish among them. Among Australia, East Timor and Indonesia, the potential continental shelf and exclusive economic zone tripoints are in different locations. The abbreviations "CS" and "EEZ" have been used to distinguish these tripoints. 
tripoint relationship exists, the names of likely third states are shown in italics. ${ }^{165}$

Endpoint Technique The endpoint technique used by the parties is indicated by the symbol in the "endpoint technique" column. A detailed description of each technique is provided in the body of this report. As with the application of the ranking system, every attempt has been made to apply these five endpoint techniques consistently across all of the endpoints considered in this table.

Associated Bilateral Relationships The three bilateral relationships associated with each tripoint are indicated in the "associated bilateral relationships" column. The relationships are listed in chronological order on the basis of signature date, or date of judgment. In some situations the same two parties have concluded two agreements sequentially in order to arrive at their current endpoint position. Where this is important to the tripoint analysis, both agreements are listed. ${ }^{166}$ Where boundary agreements follow judgments, as occurred after several ICJ cases, the date of the judgment and the date of the agreement are both provided. The boundary report number for each bilateral agreement is provided in parentheses. Associated bilateral relationships that have not yet resulted in an agreement appear in this column in italics.

Remarks The information provided in the "remarks" column has been extracted from the texts of boundary agreements and judgments provided in Volumes I-V of this series. ${ }^{167}$ Where the endpoint information consists only of coordinates, those have been provided in a standardized format. ${ }^{168}$

165 See, for example, North Korea-Russia-Japan or South Korea.

For the purpose of this table the "likeliness" of a tripoint relationship among two parties to a bilateral agreement and one or more states in the vicinity of that agreement has been determined only in terms of general coastal relationships. No systematic geodetic measurements have been made to find equidistant tripoint locations, nor have detailed studies been made of all sovereignty disputes that could impact tripoint relationships. There has been no intention to support or endorse territorial claims or boundary positions in the choice of the states likely to be involved in a tripoint relationship.

166 See, for example, the two agreements between India and Sri Lanka - one before and one after the conclusion of the India-Maldives-Sri Lanka tripoint agreement.

167 In order to provide important endpoint-related language, it was necessary to go outside the pages of this series to the full text of the judgments in Libya v. Malta and Eritrea/Yemen.

168 Standardizing the coordinates has involved inserting symbols in place of the words "degrees," "minutes" and "seconds," and, where the intention of the parties appears unambiguous, moving the location of minute and second symbols to their appropriate locations. Only in the case of the India-Maldives-Sri Lanka tripoint and its associated boundaries was it impossible to ascertain the appropriate format. 
Where additional endpoint information is available in the treaty or judgment text, it has been quoted faithfully from the pages of this series. ${ }^{169}$ The page numbers are provided in parentheses.

Secession and Unification The break ups of the Soviet Union and Yugoslavia, and East Timor's independence have created several new tripoint relationships. It is assumed for the purpose of this table that states formed by these dissolutions, unless they have declared otherwise, are successors to the boundary agreements of their predecessor state. Russia, ${ }^{170}$ Ukraine $^{171}$ and Georgia ${ }^{172}$ are considered to be successor states to the Soviet Union. Likewise, Slovenia, ${ }^{173}$ Croatia, ${ }^{174}$ and Serbia and Montenegro are considered to be successor states to Yugoslavia. Where specific endpoint information is available, it has been included in the table. Where successors have succeeded to the "relevant part" of a preexisting boundary without further defining that part, the page numbers of the preexisting boundary have been provided.

Estonia, Latvia and Lithuania have indicated that they are not successors to the Soviet Union. ${ }^{175}$ Therefore, the boundaries of the Soviet Union in the Baltic Sea with Finland and Sweden have not been attributed to them in the accompanying table. Similarly, East Timor claims to be a suc-

169 In the interest of space the language is abridged to include only information directly relevant to the topic at hand. This has resulted in some disjointed sentences. The reader is encouraged to study the complete texts at the page numbers indicated.

170 "[T]he Russian Federation continues to exercise its rights and honour its commitments deriving from international treaties concluded by the Union of Soviet Socialist Republics." Report Number 8-10(4) at 2443. It should be assumed that this statement applies to all of Russia's boundary relationships including with Turkey in the Black Sea, North Korea in the Sea of Japan, and Finland, Sweden and Poland in the Baltic Sea. See Report Number 8-10(4) regarding the boundary relationship between Russia and Turkey. See Report Number 10-14 regarding Russia's successor state status in the Baltic Sea.

171 "Ukraine, in accordance with international law and with its legislation, is a successor state of the [Soviet Union] equally with all other states of the [Soviet Union]." Report Number 8-10(4) at 2445 .

172 Report Number 8-10(5).

173 "The state frontiers of the Republic of Slovenia are the internationally recognized state frontiers between the hitherto SFRY and ... the Republic of Italy ... in that part of the frontier in which these states border on the Republic of Slovenia." Report Number 8-7(3) at 2440.

174 "International agreements concluded and acceded to by the SFRY shall apply in the Republic of Croatia ... on the basis of the provisions of the international law on state succession relating to international agreements.... The state boundaries of the Republic of Croatia are the internationally recognized state boundaries of the present-day SFRY in the part which relates to the Republic of Croatia." Report Number 8-7(3) at 2441-42.

175 Report Number 10-14 at p. 2562. See also Erik Franckx, Region X Report, infra. 
cessor to Portugal, not to Indonesia. ${ }^{176}$ Therefore, the boundaries between Australia and Indonesia have not been attributed to East Timor in the table below, except where they have been renegotiated by East Timor. ${ }^{177}$

Unification can have the opposite effect on tripoint relationships. German unification eliminated a potential tripoint among Denmark, the Federal Republic of Germany and the German Democratic Republic.

176 Report Number 6-15 at 2756-57.

177 Report Number 6-15, 6-20. 
ROBERT_f6-3305-3375 2/16/05 1:16 AM Page 3346

3346

Coalter G. Lathrop
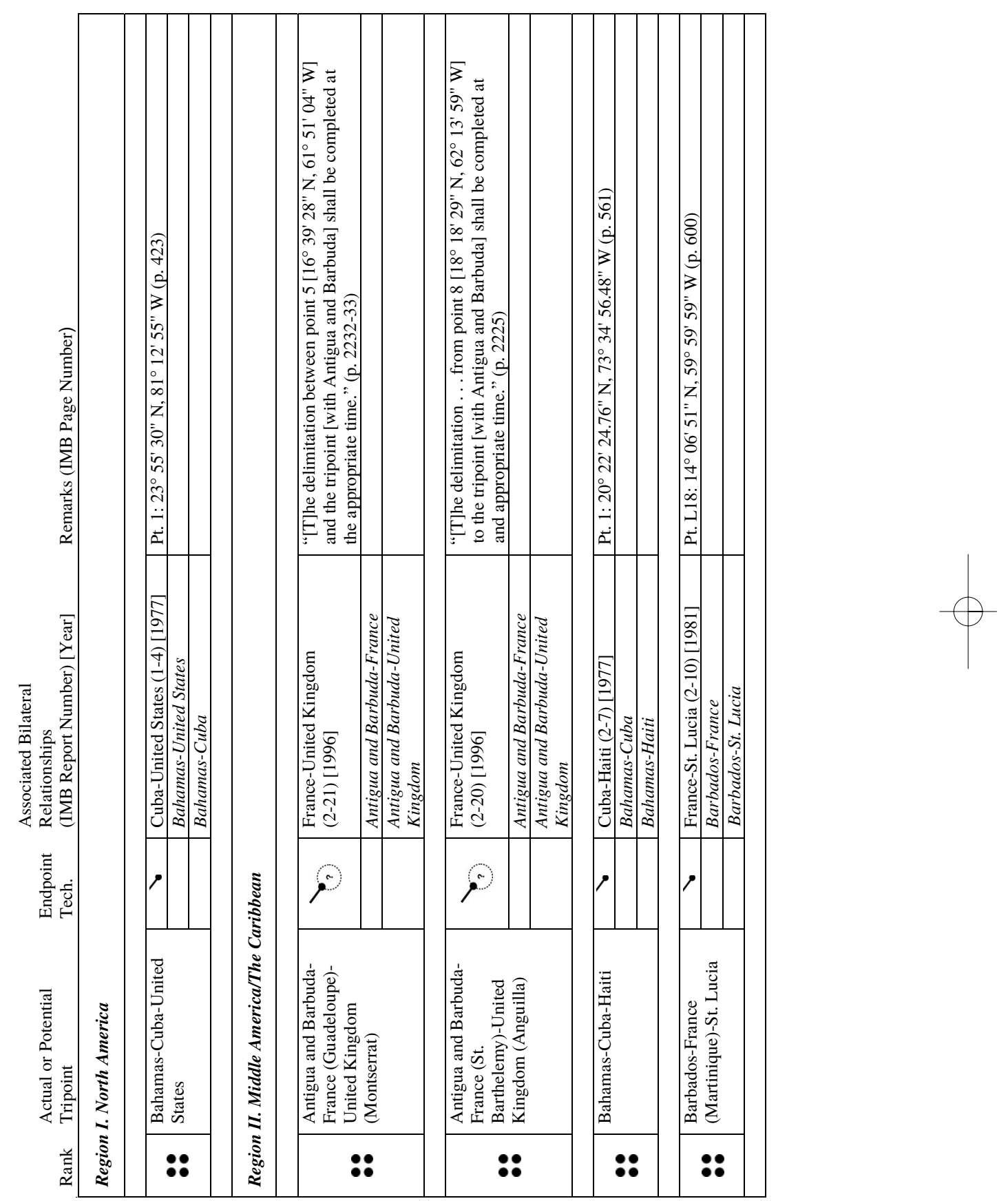


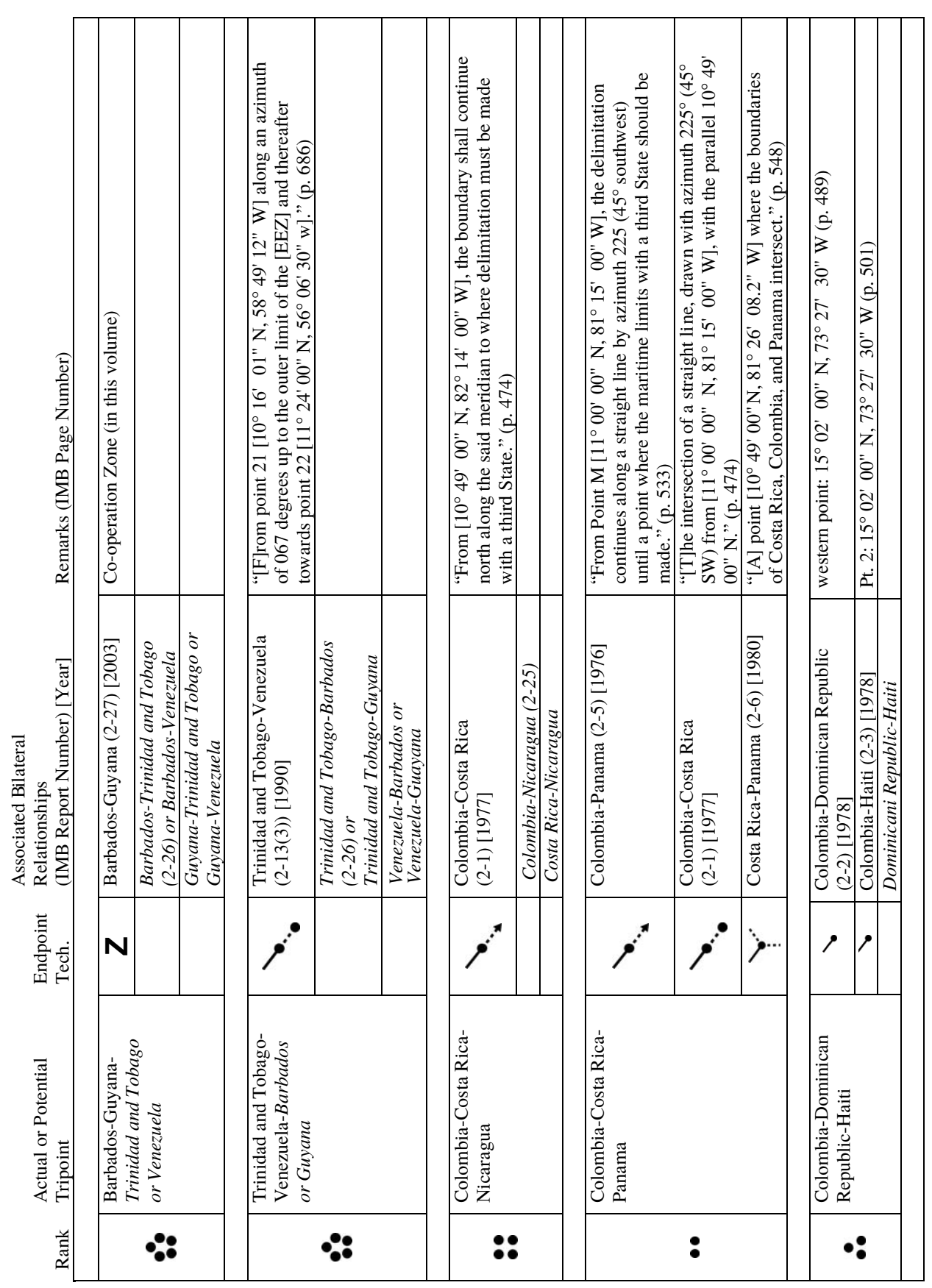


ROBERT_f6-3305-3375 2/16/05 1:16 AM Page 3348

3348 Coalter G. Lathrop
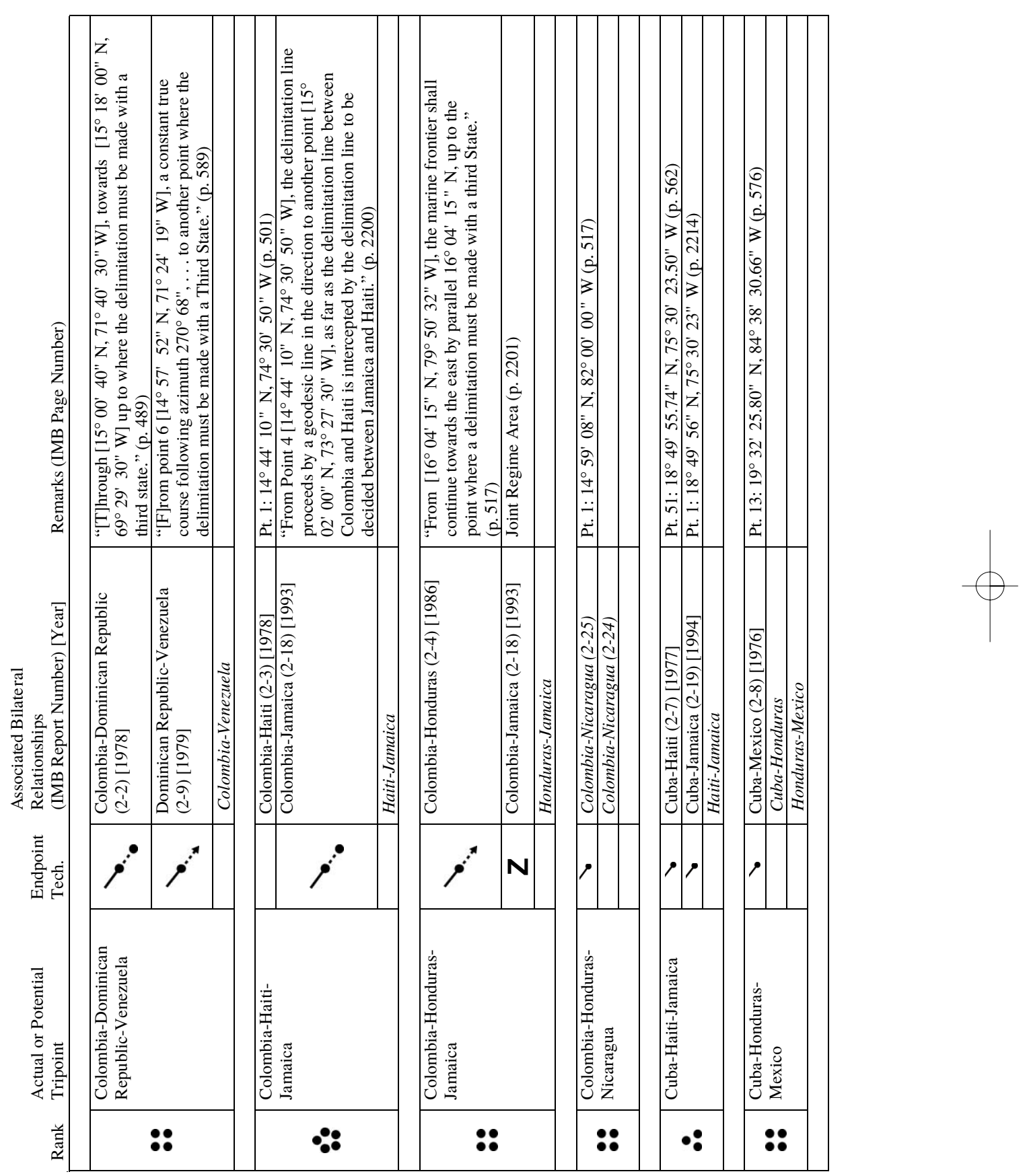

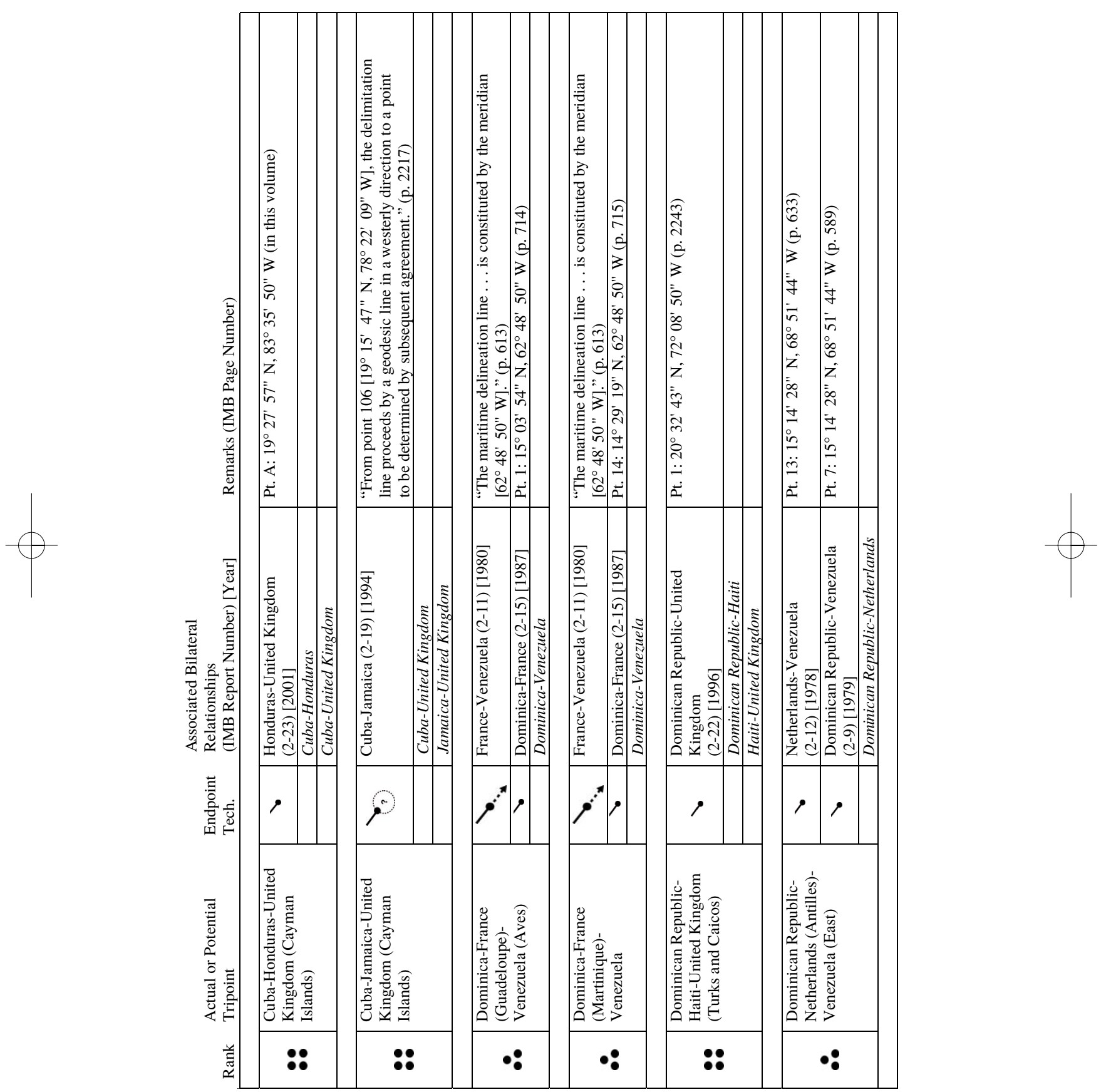


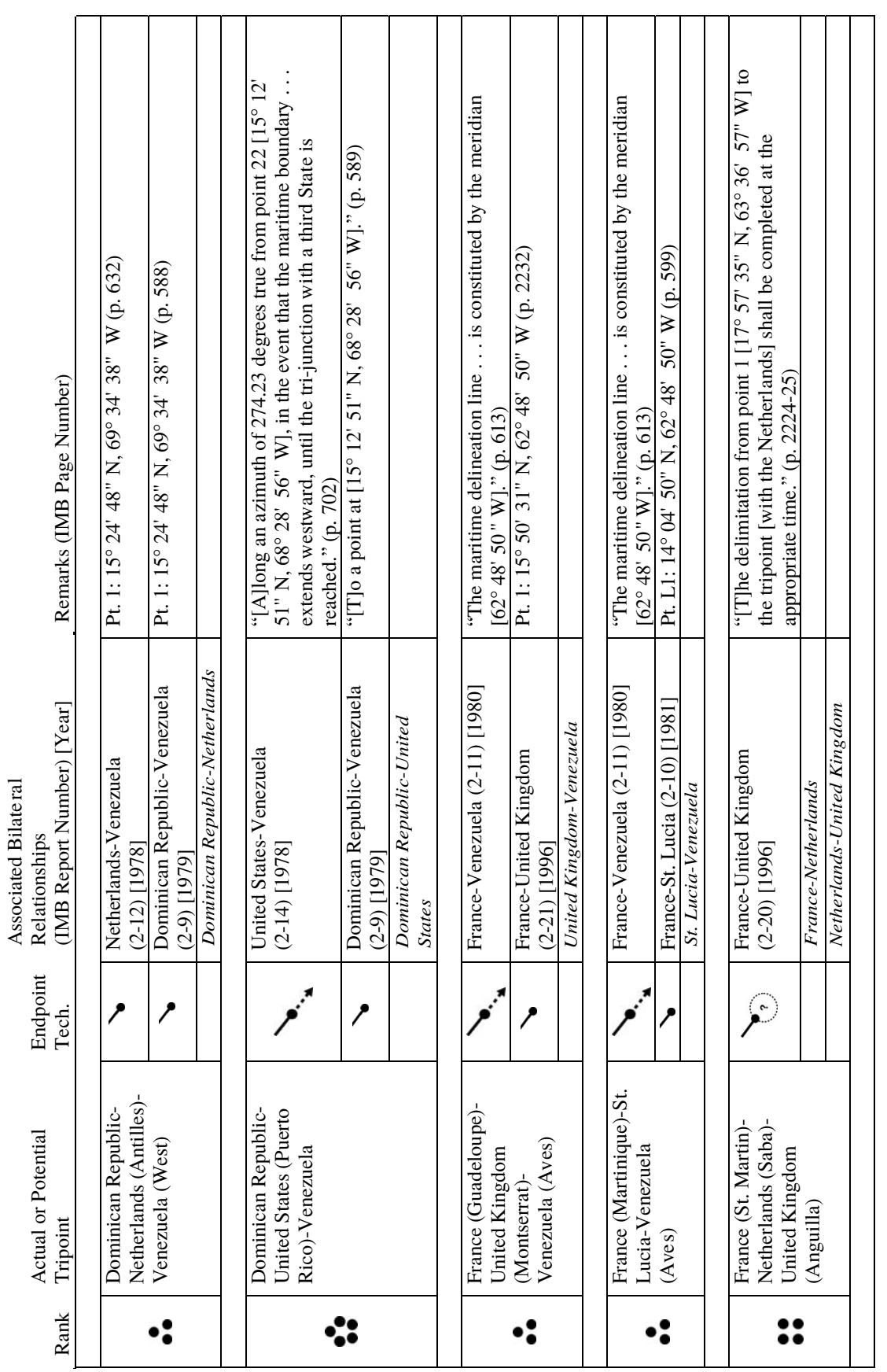




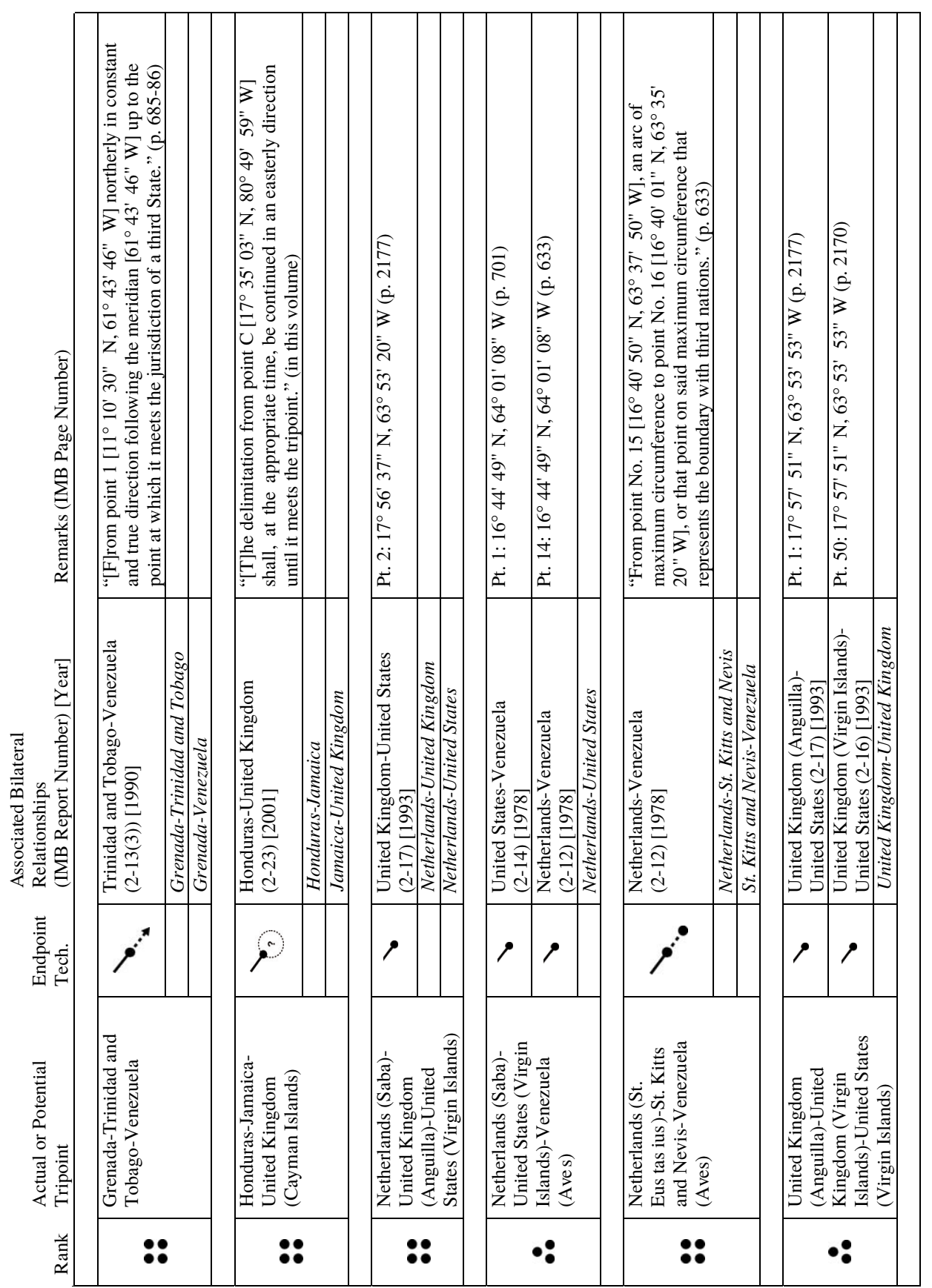



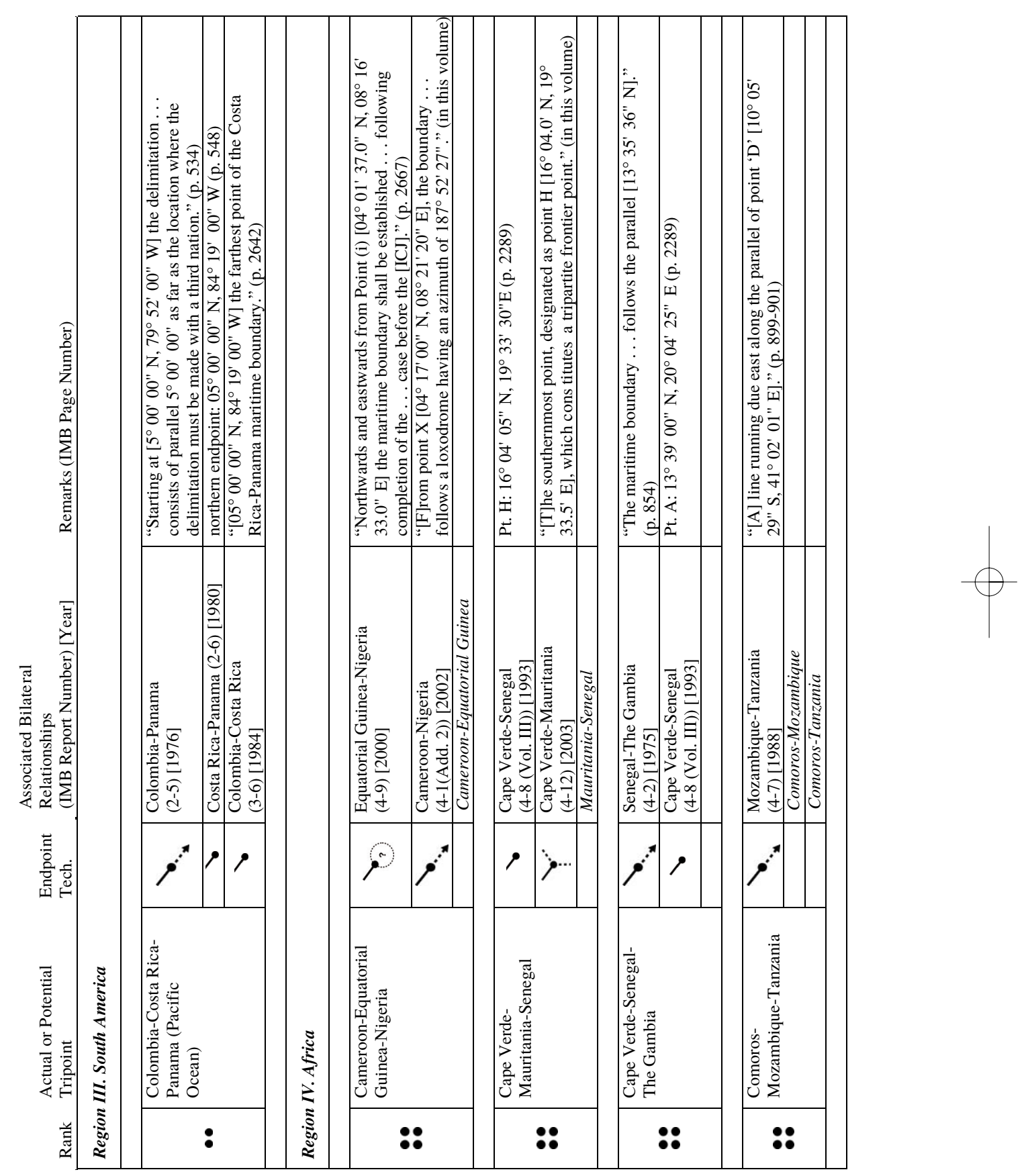

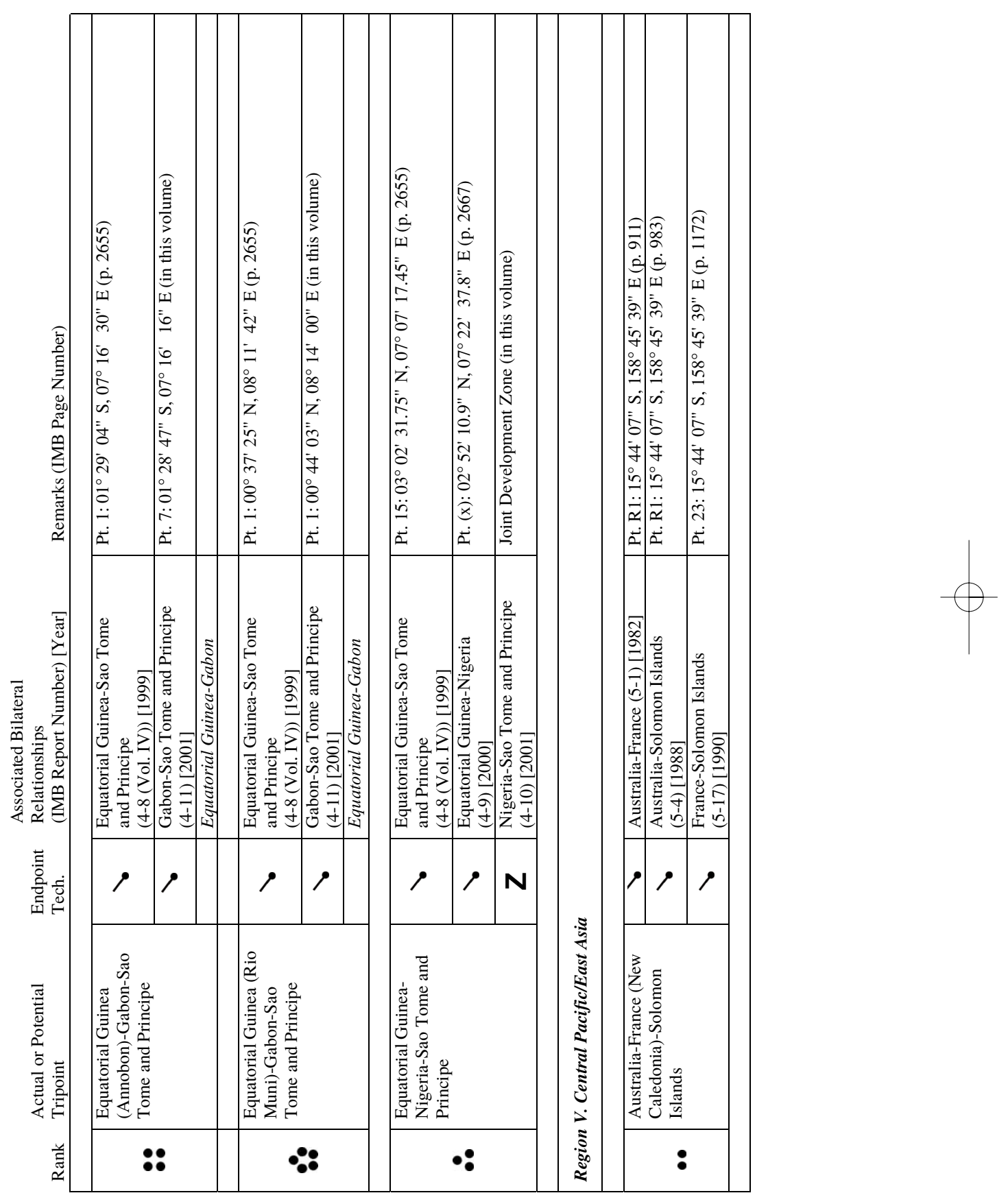


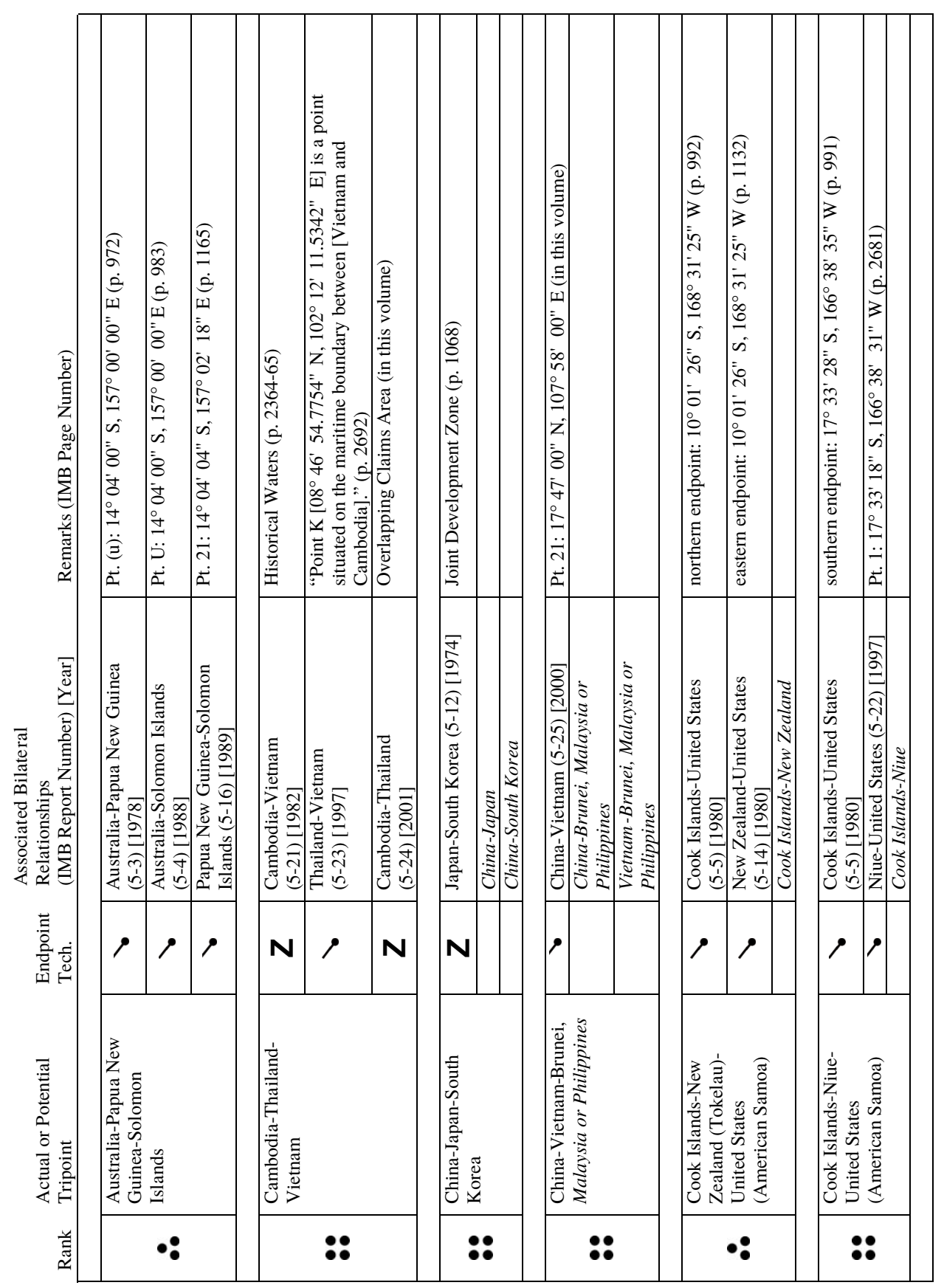



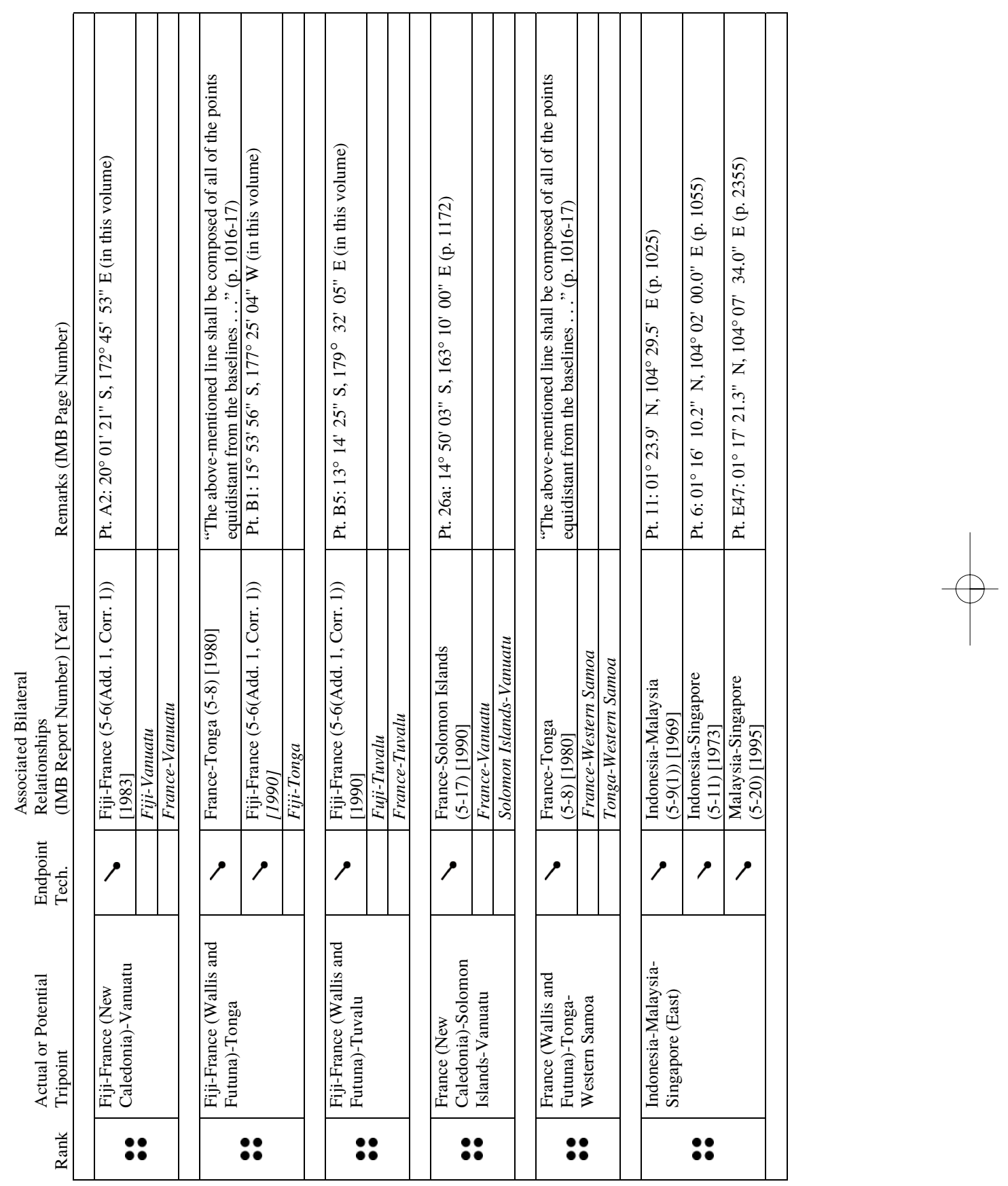

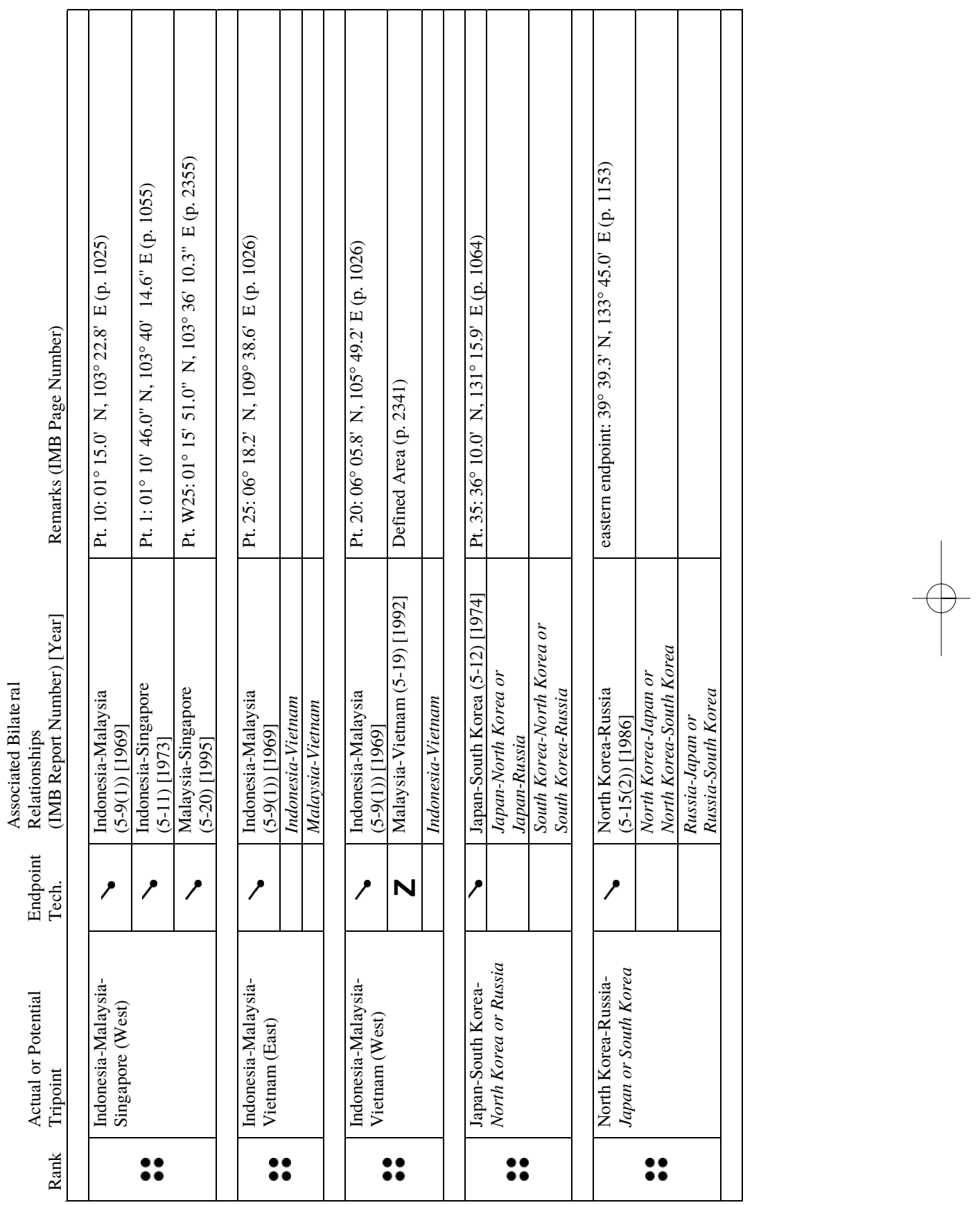

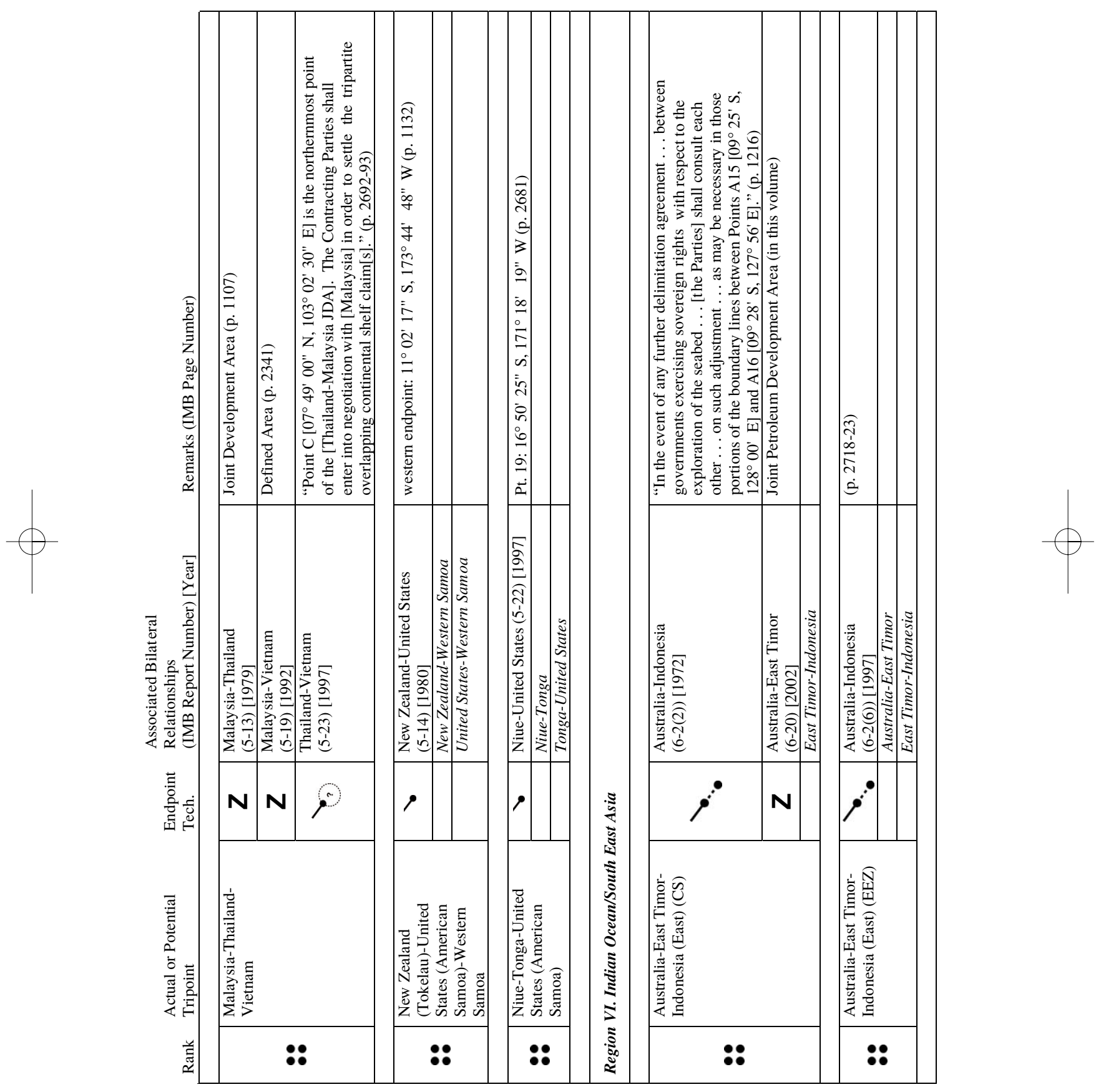


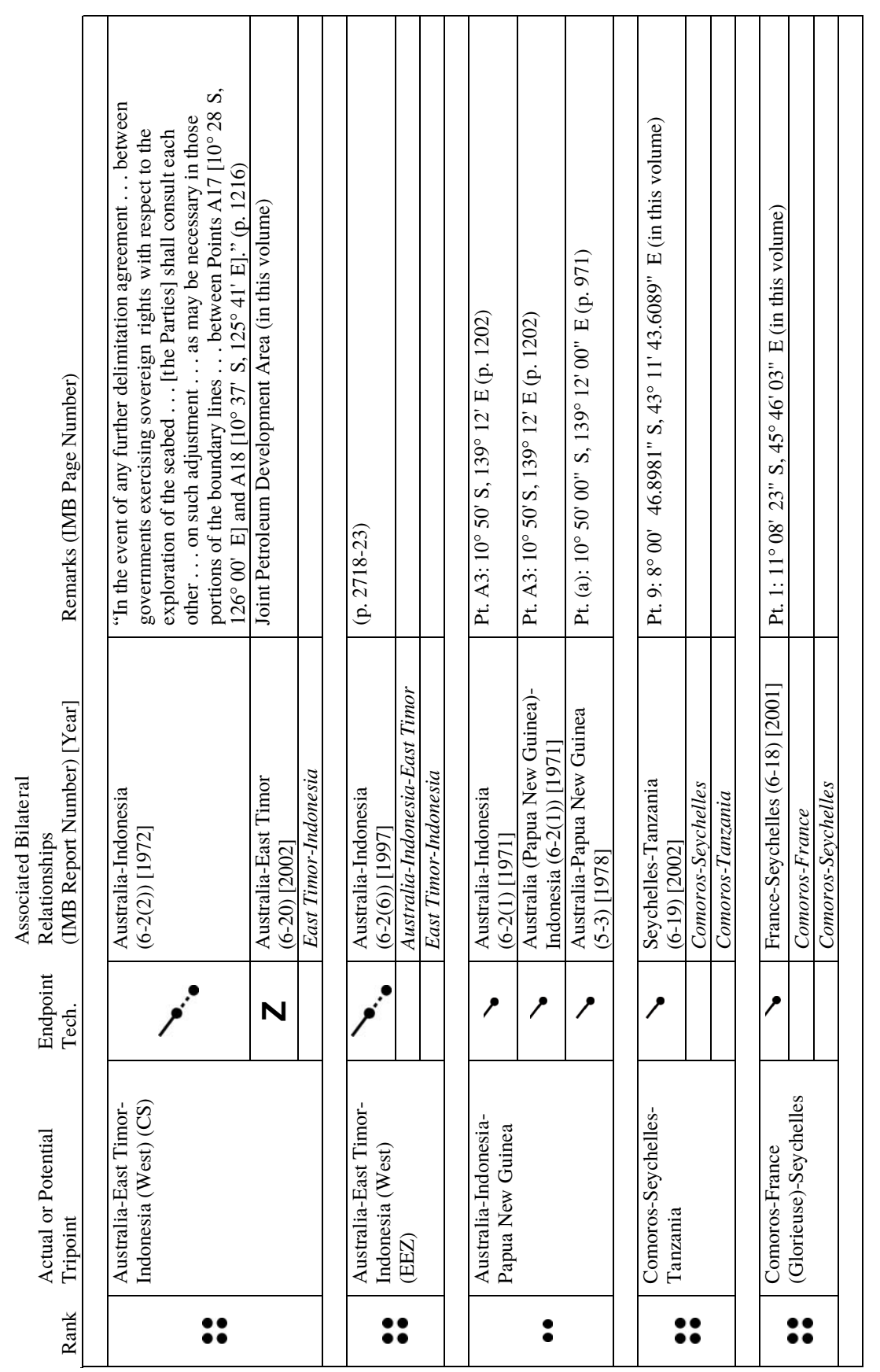



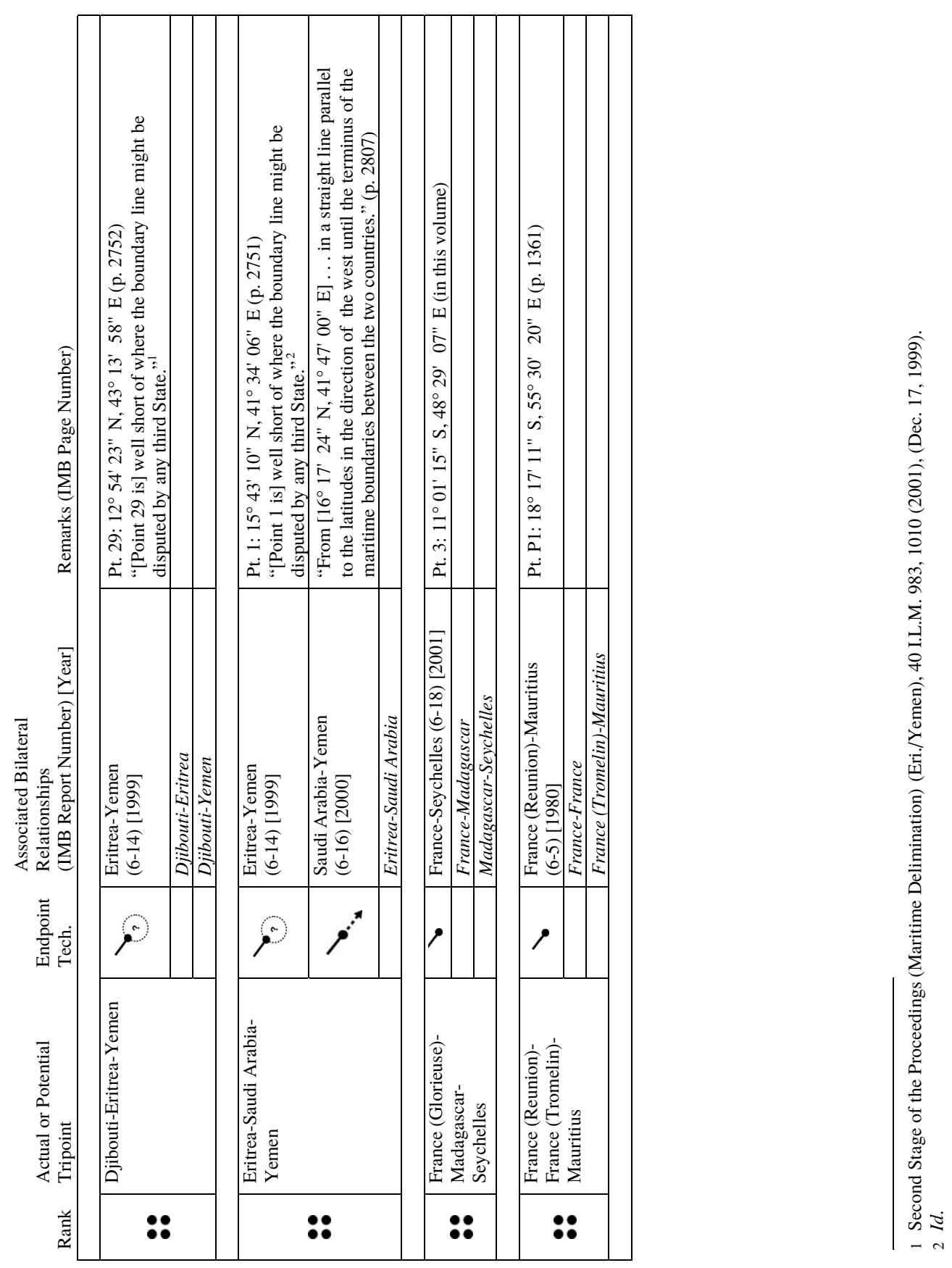

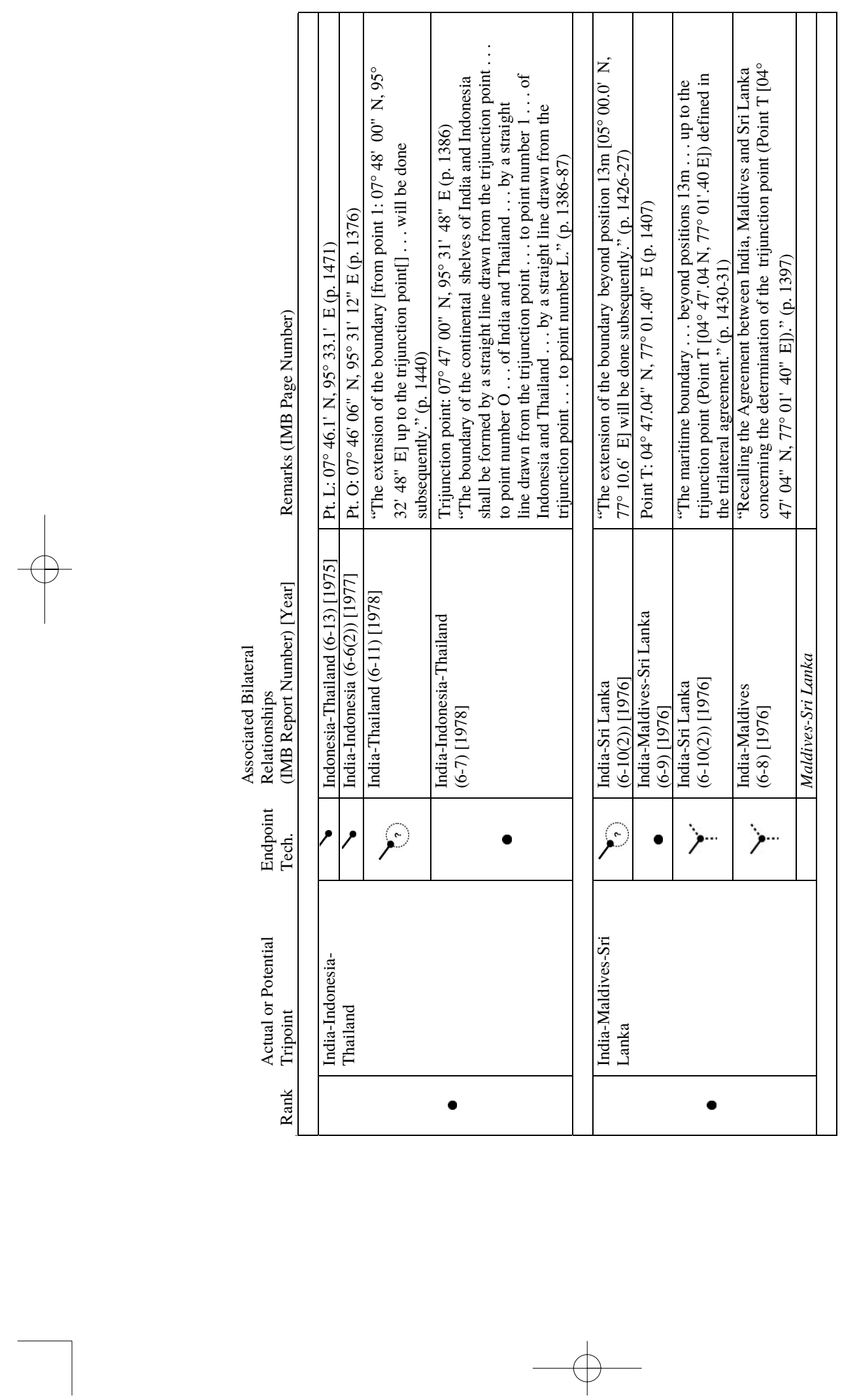


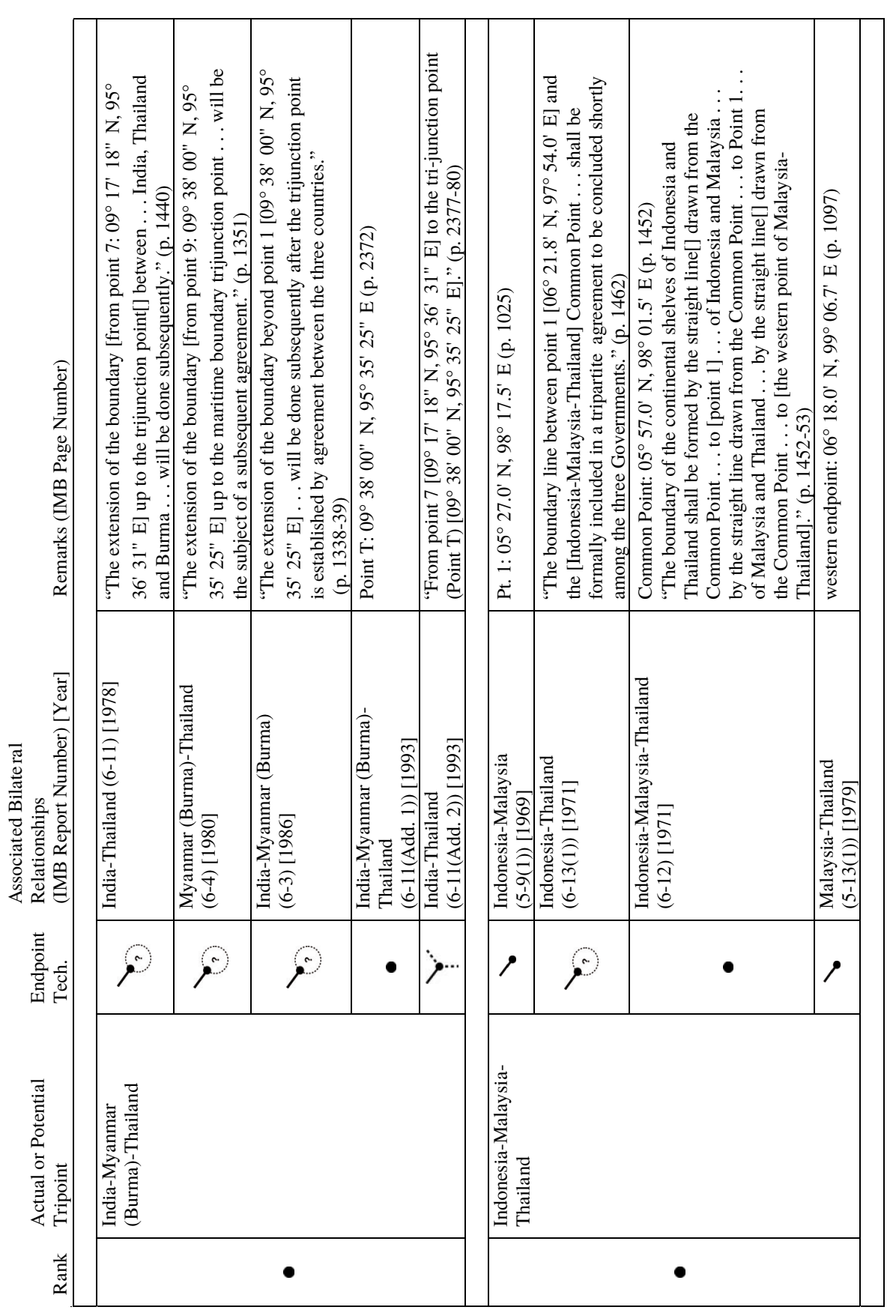



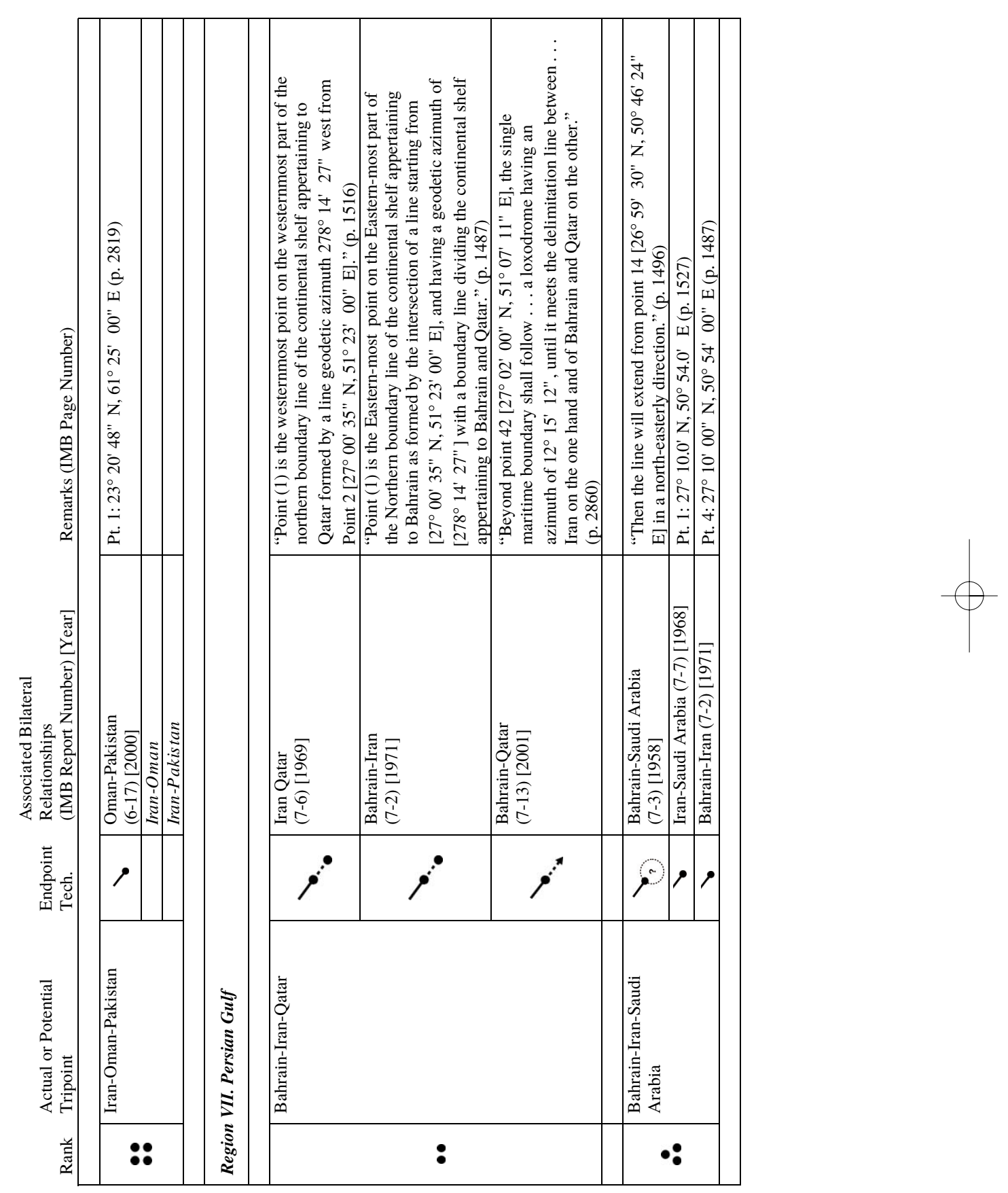

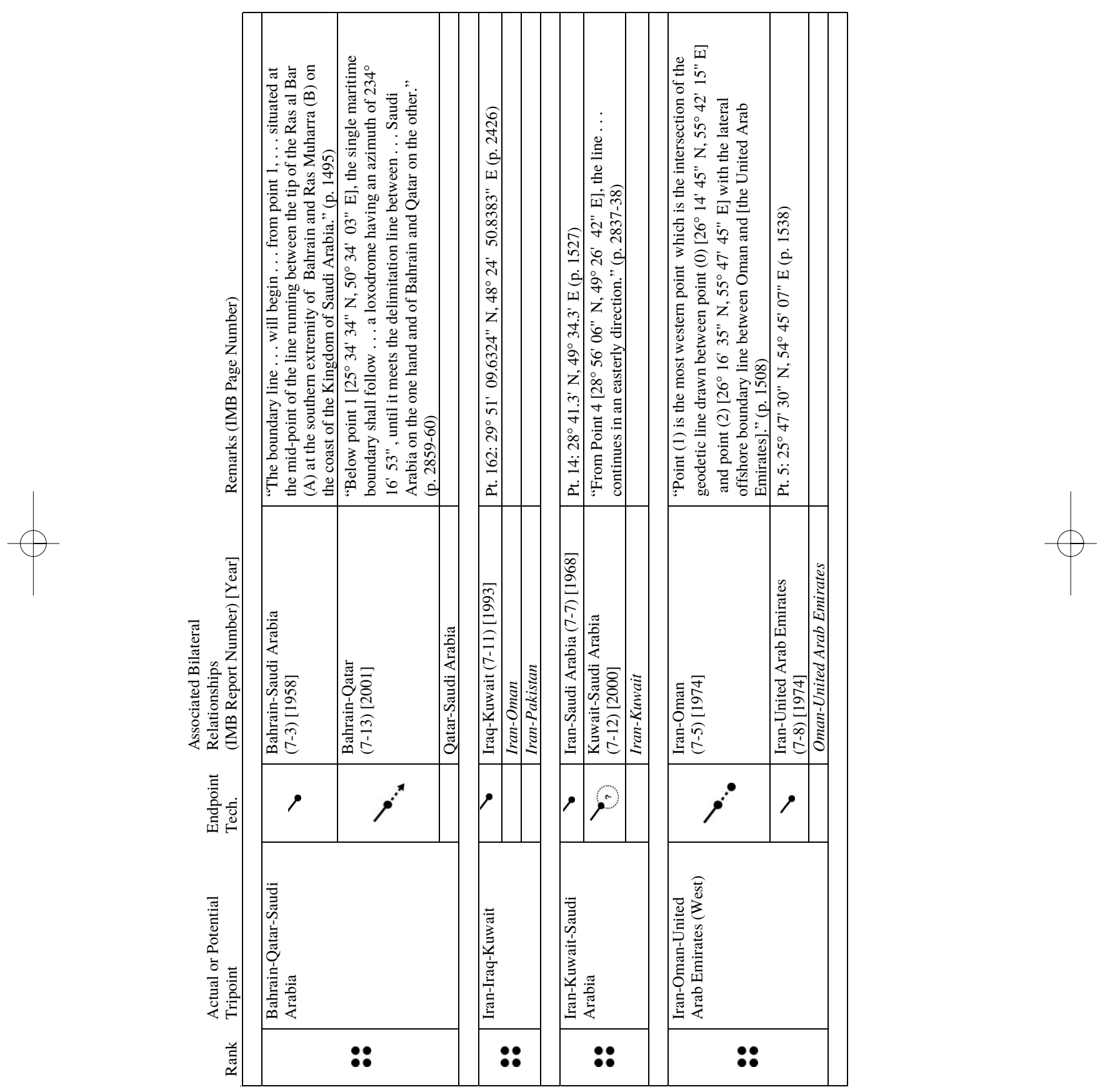

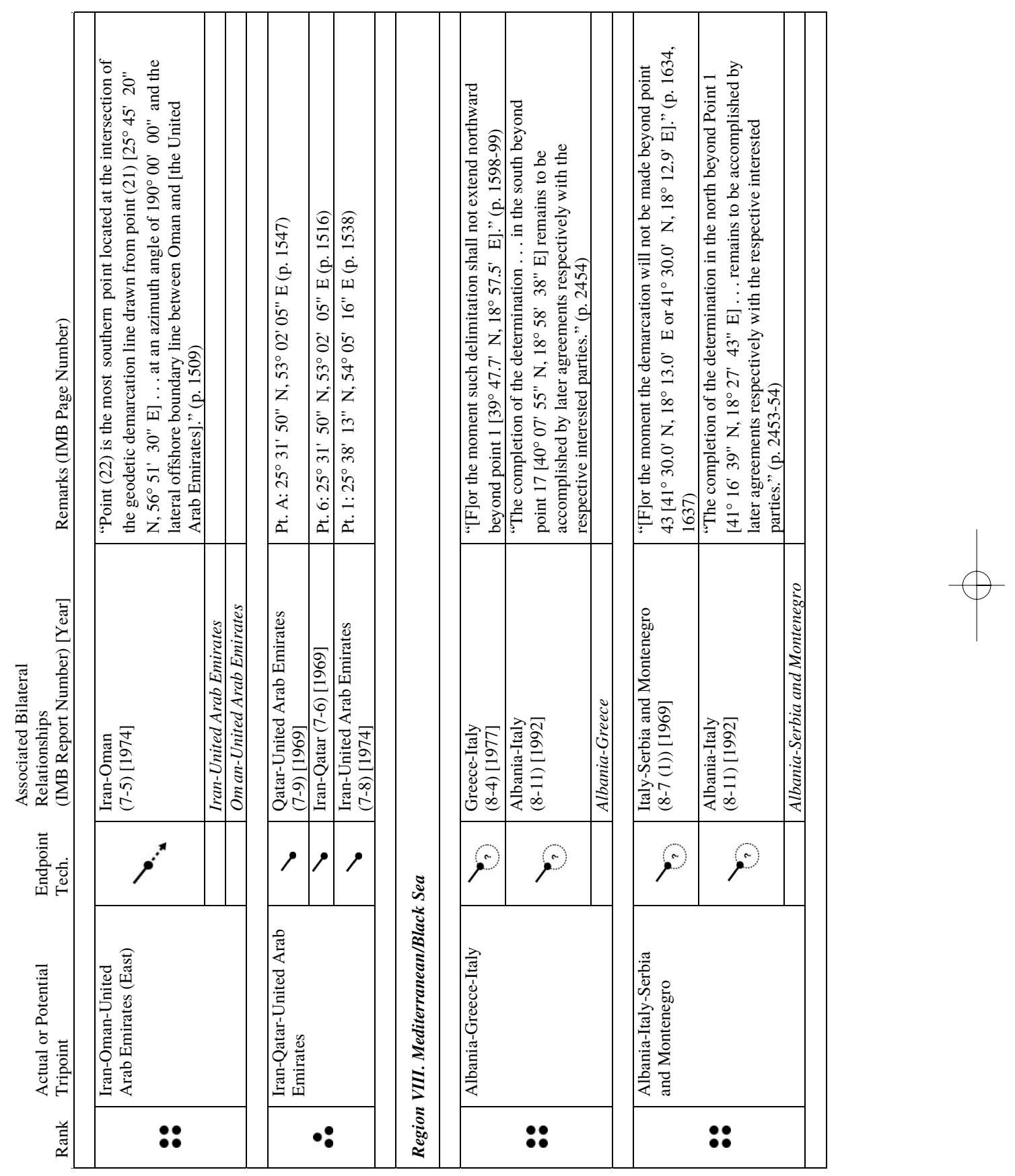

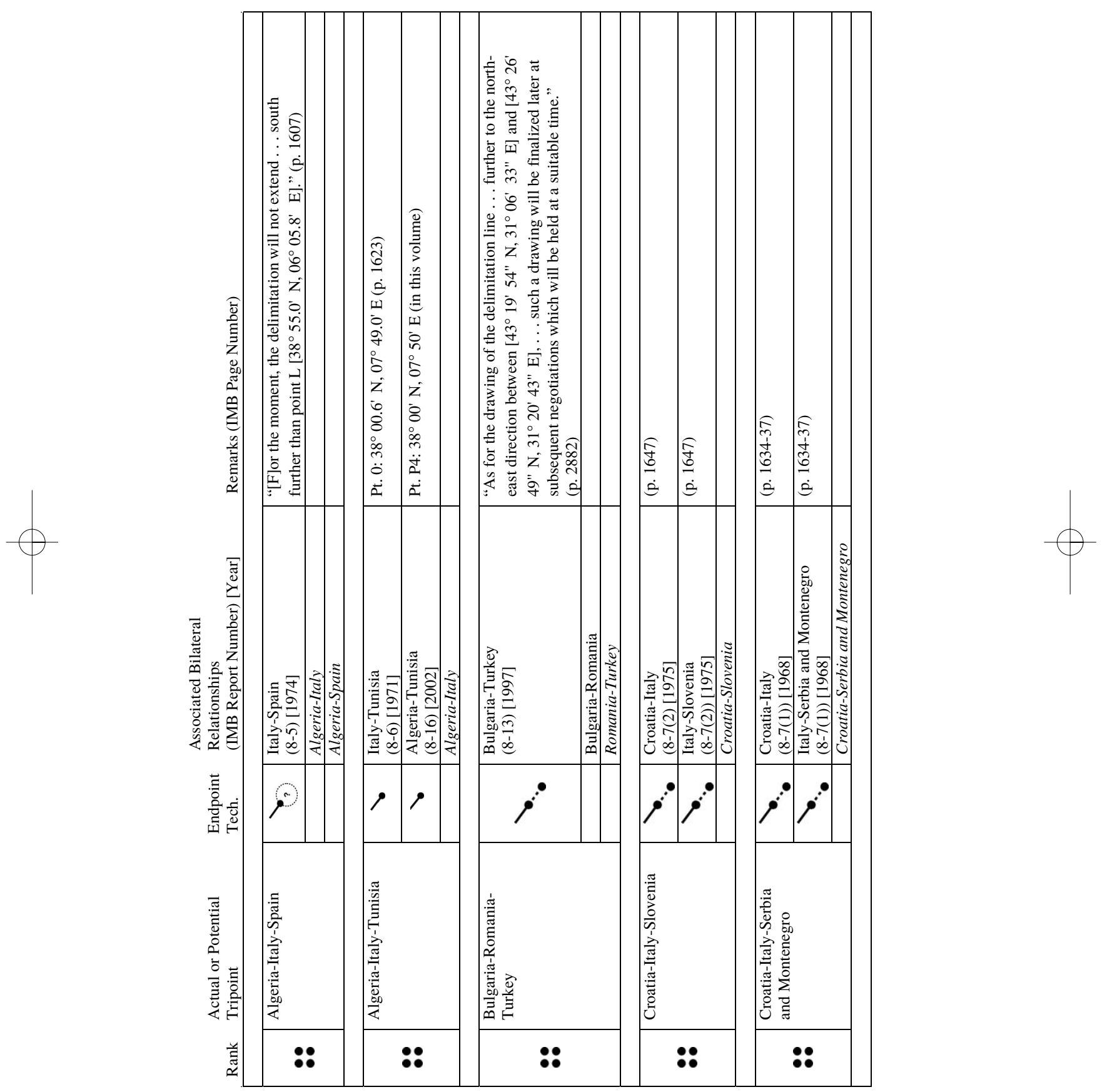


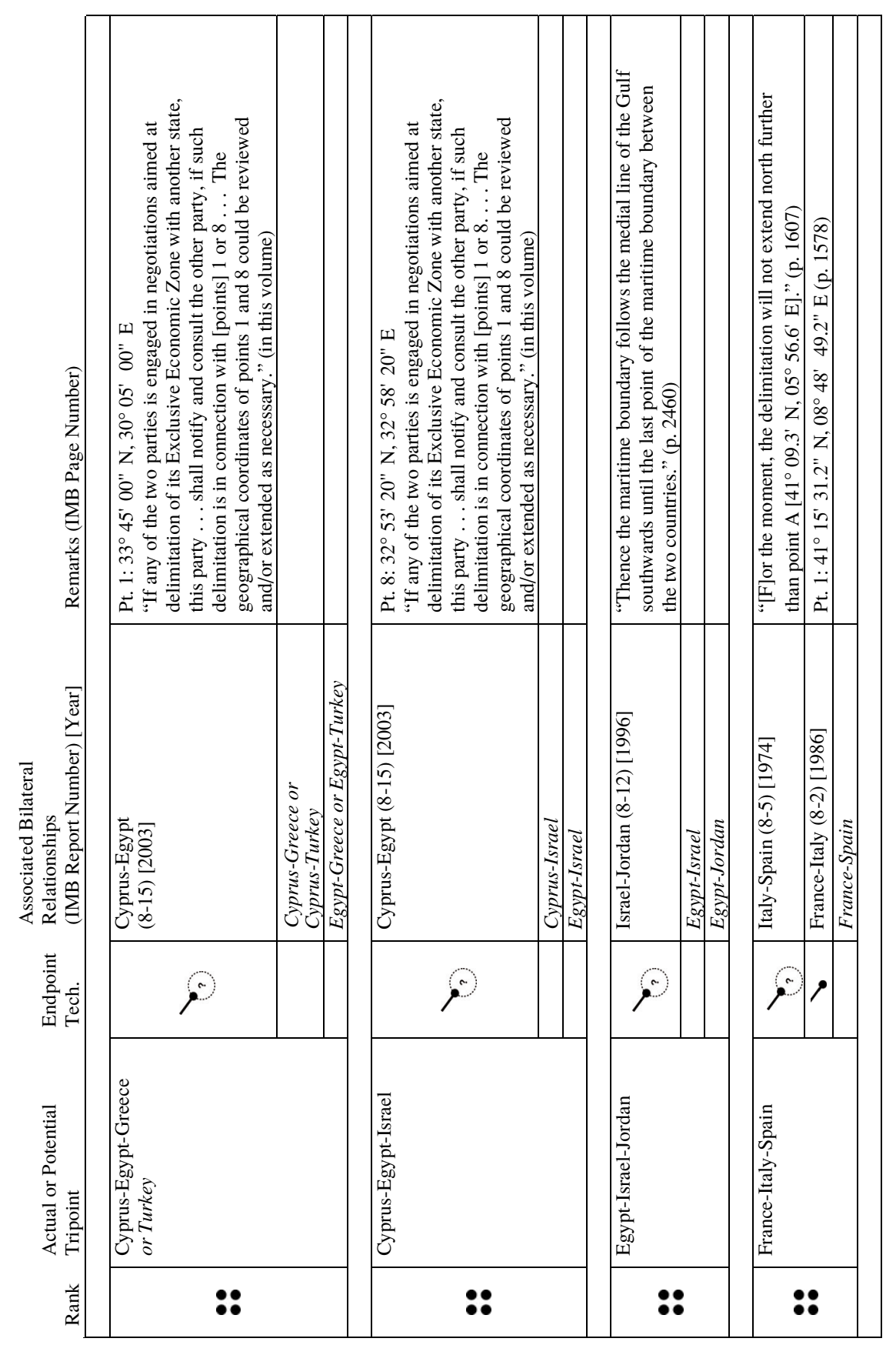



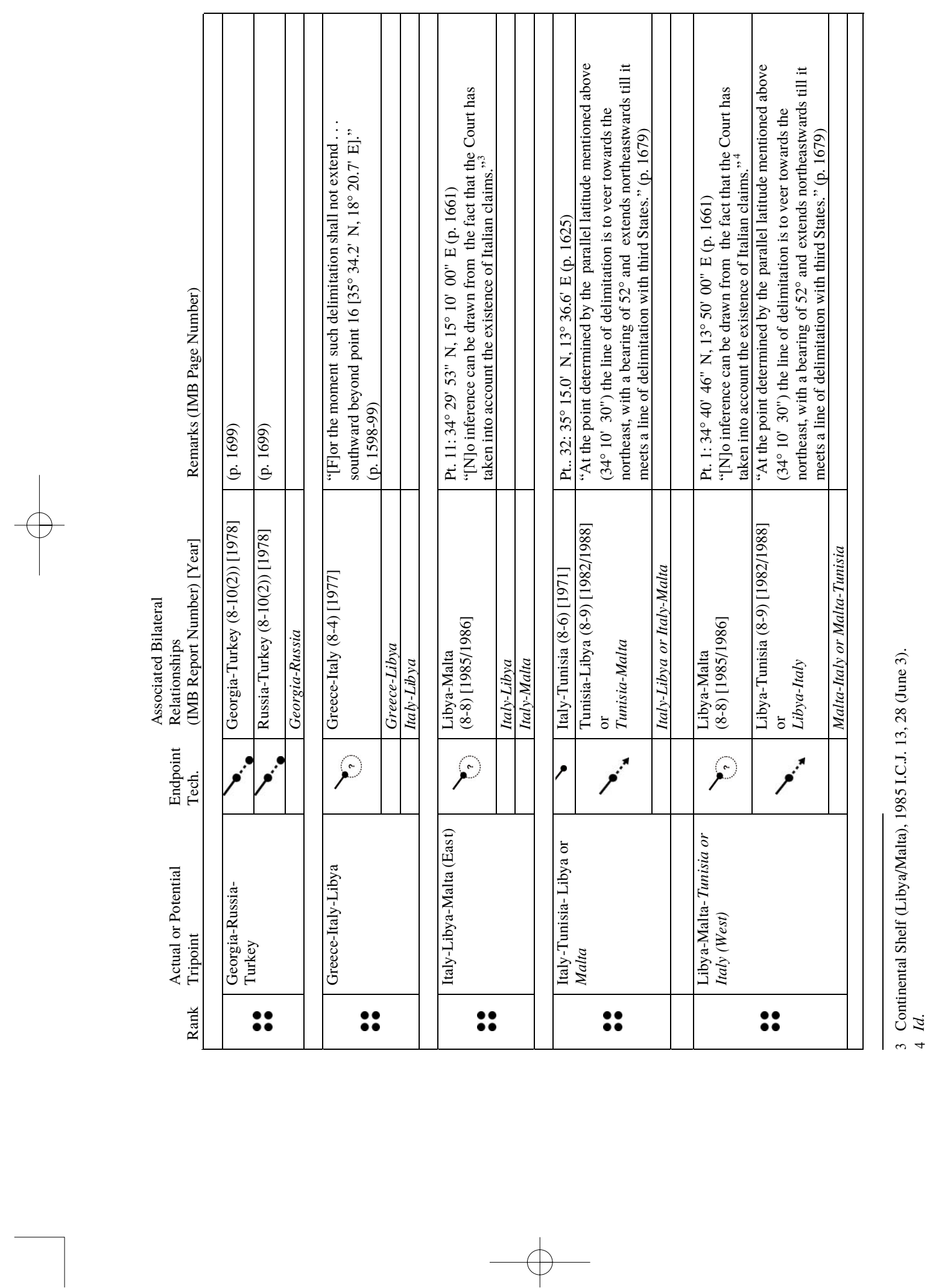

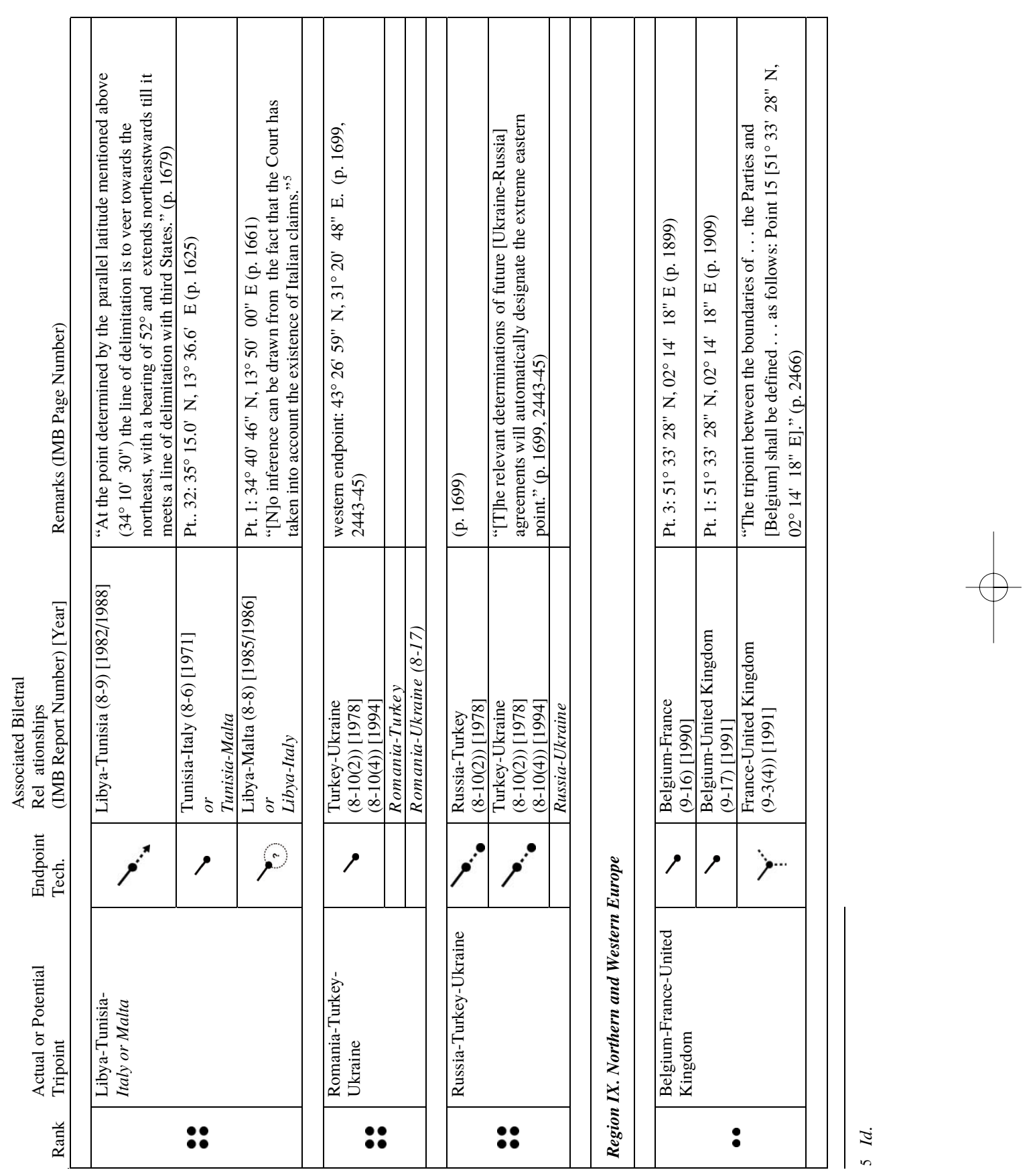

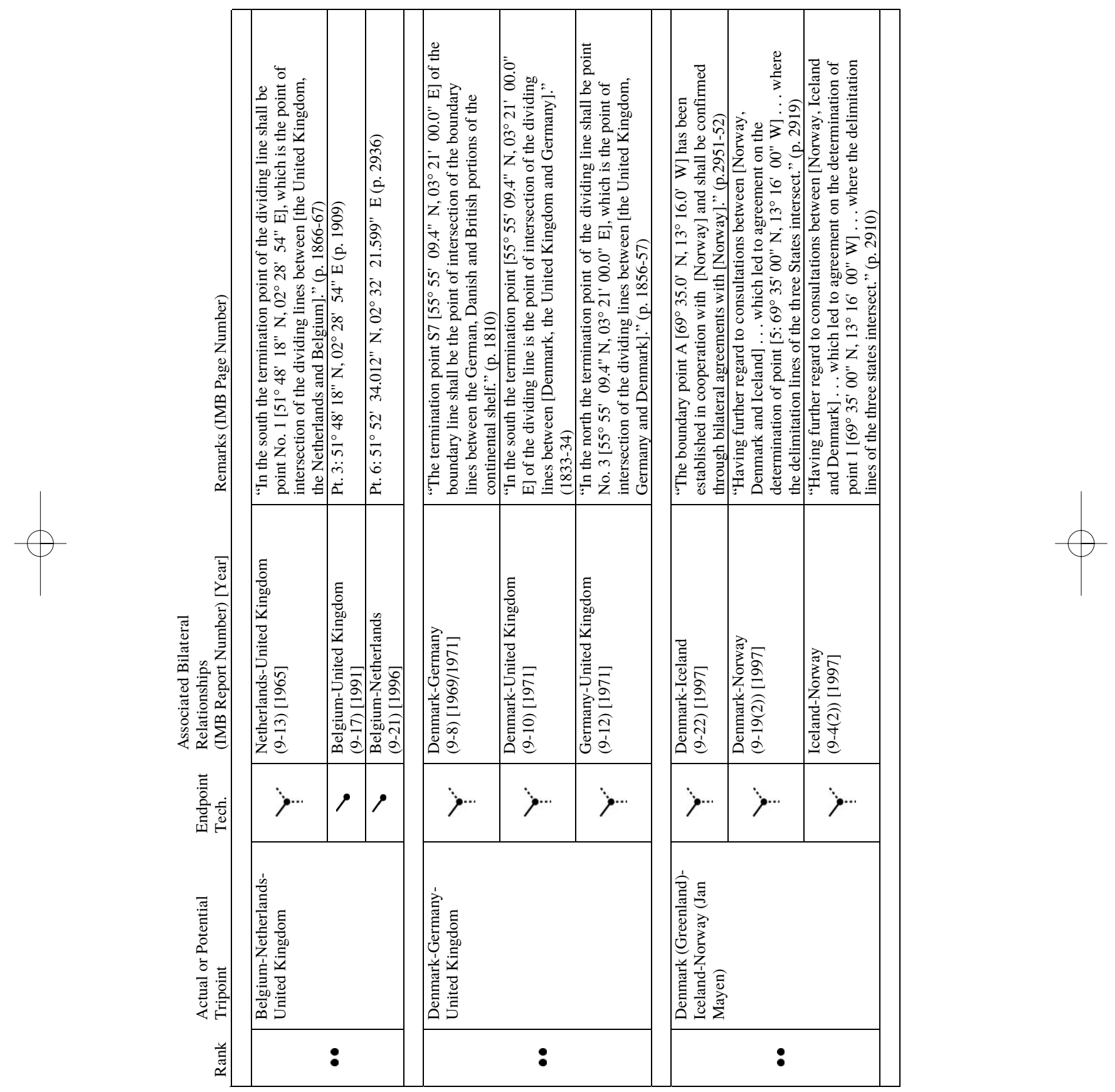


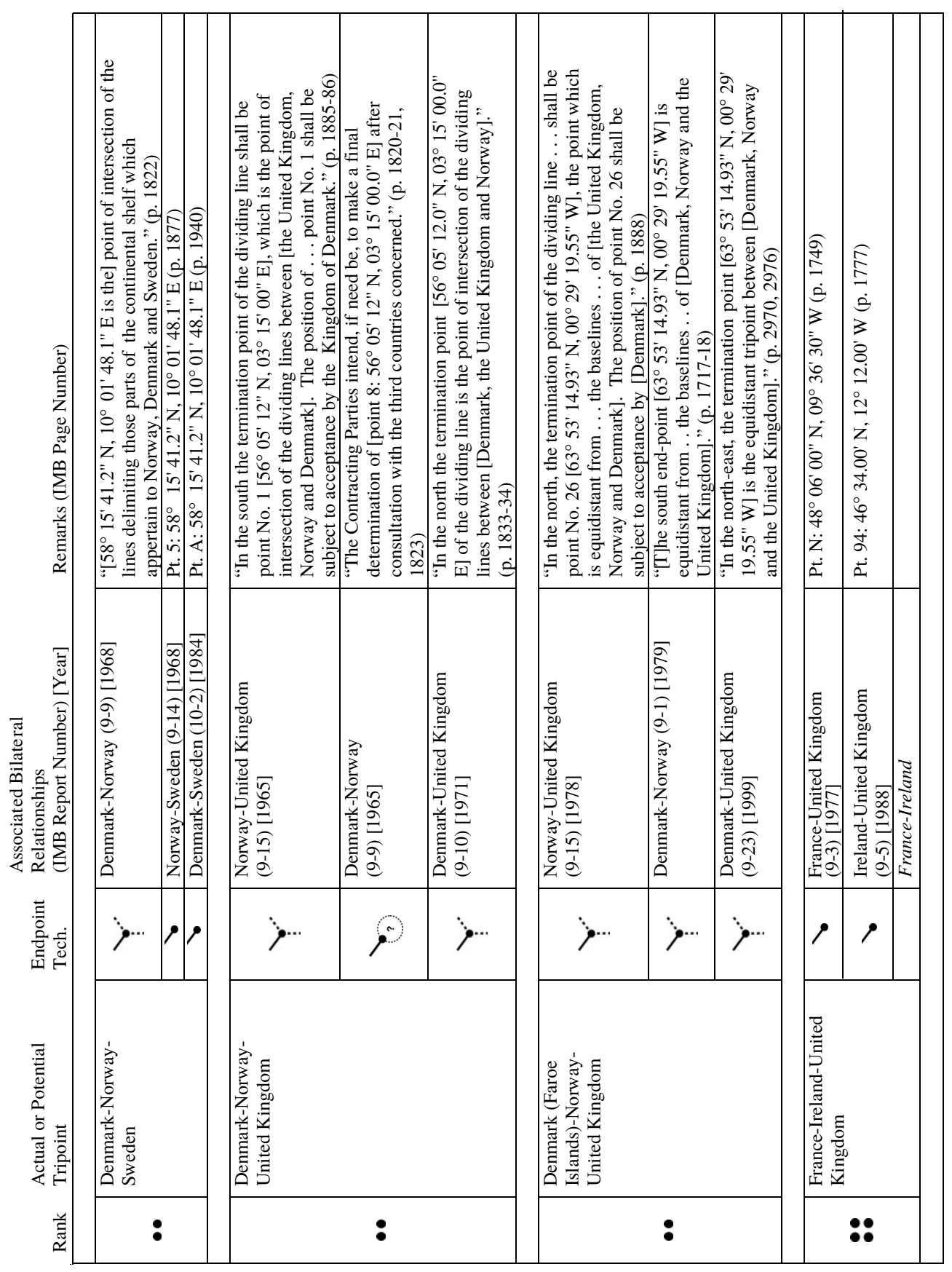



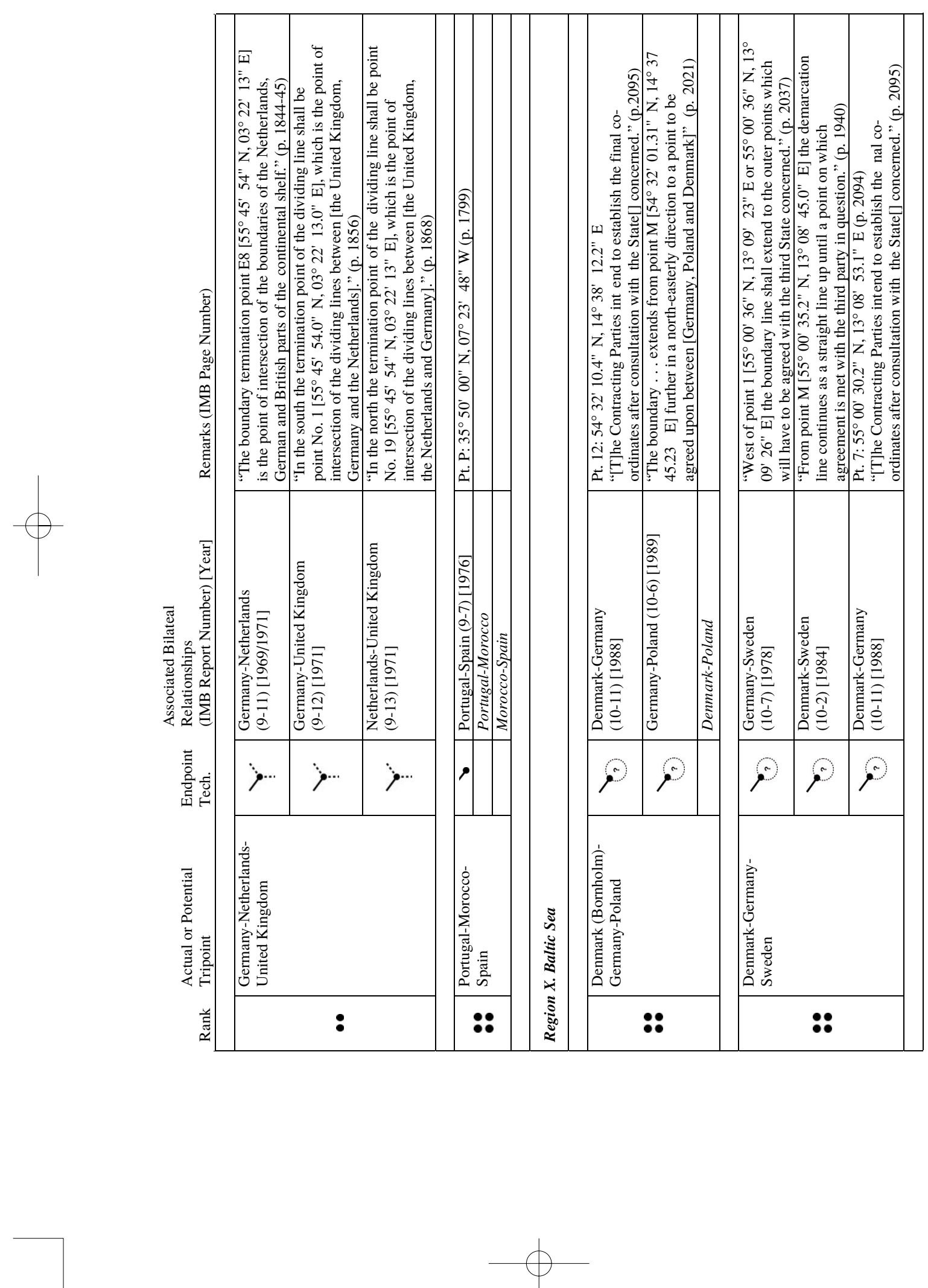

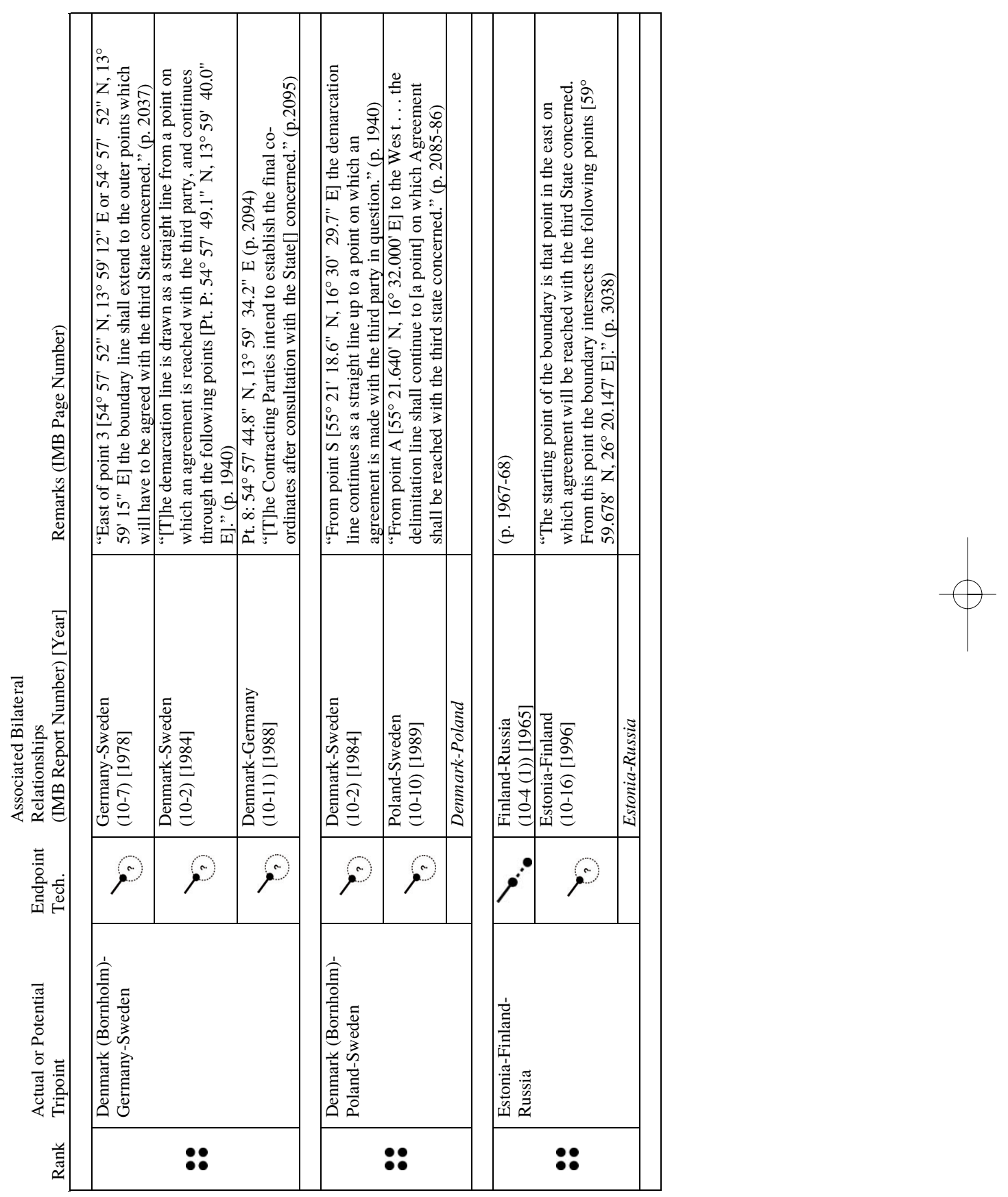

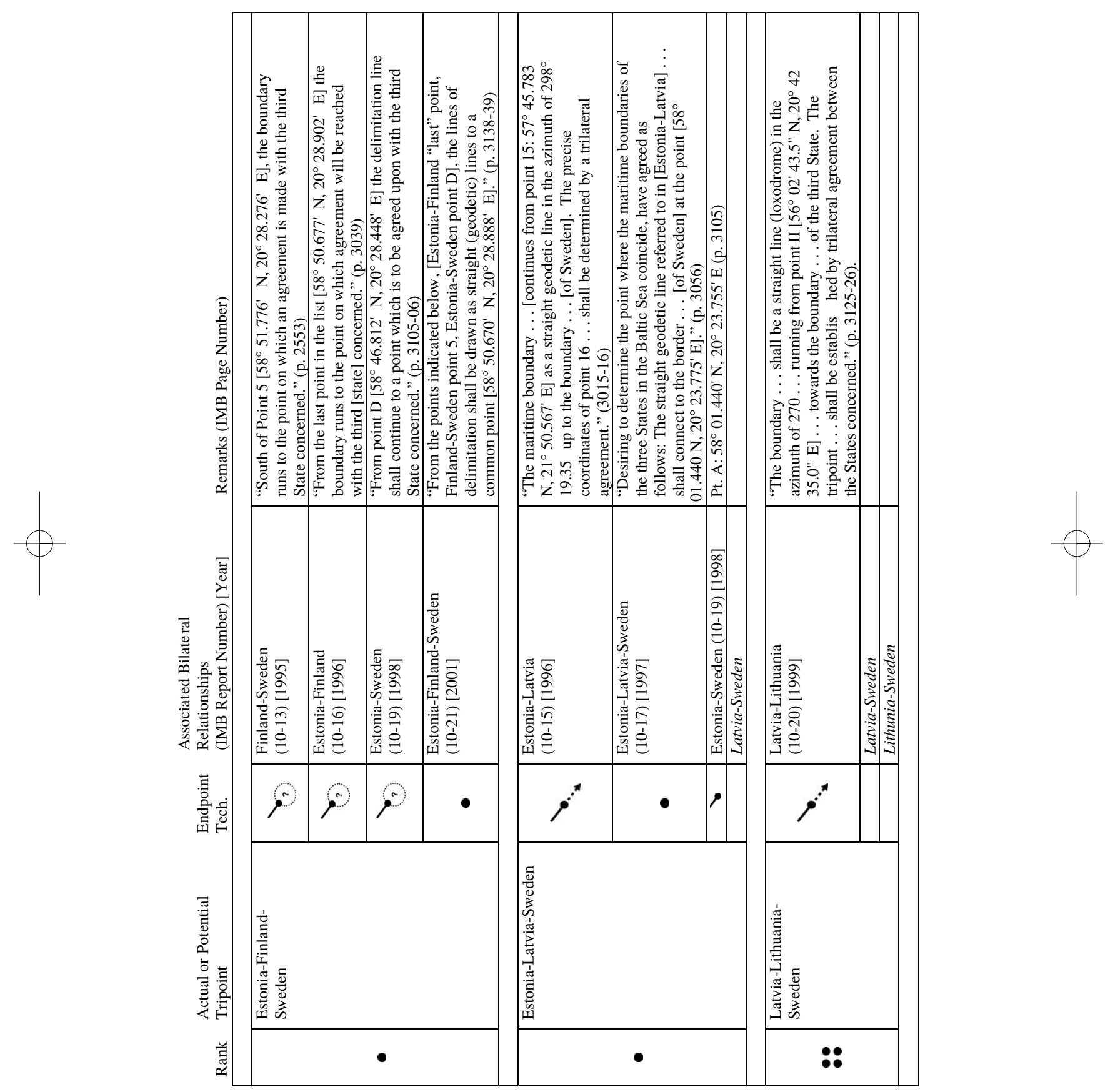

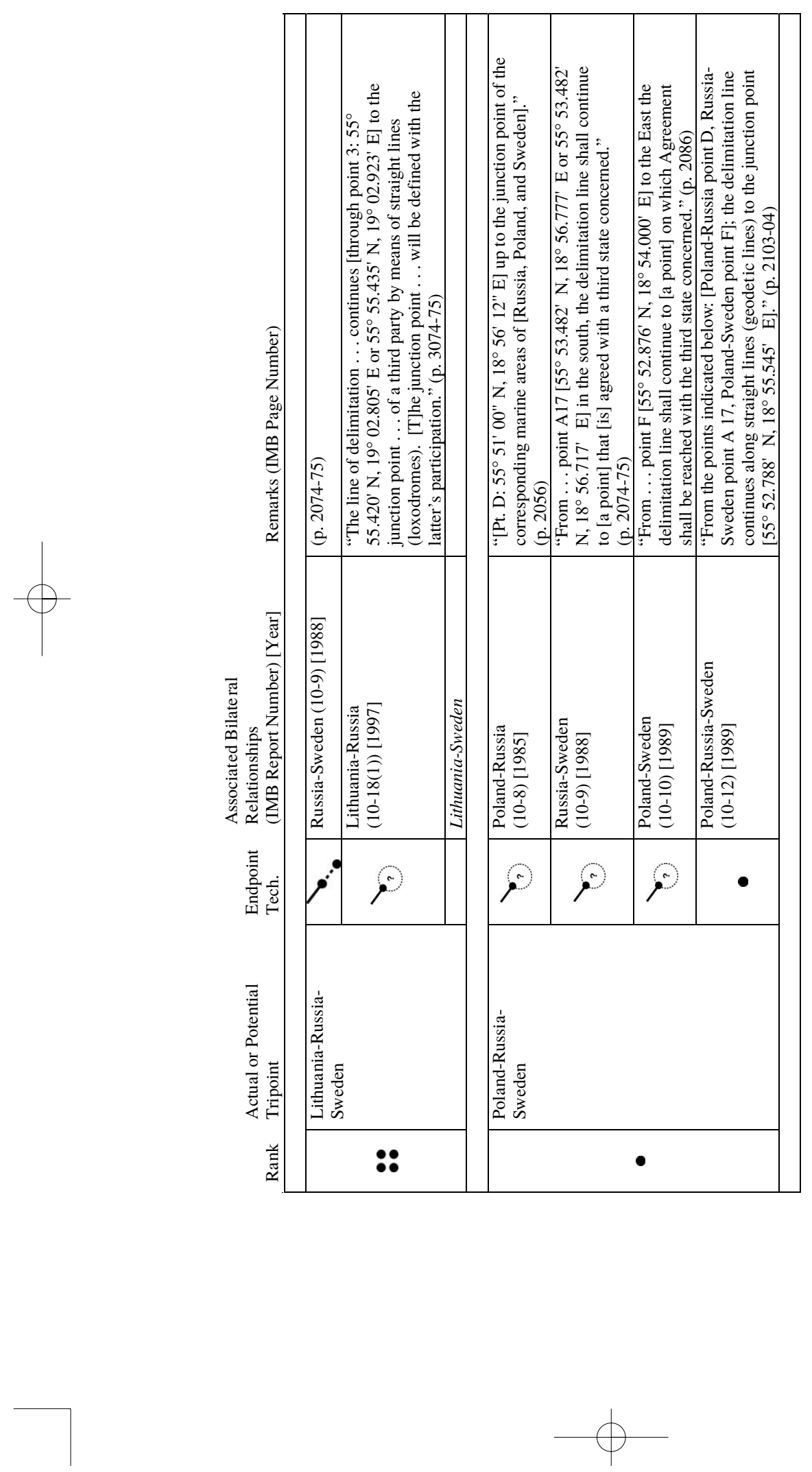

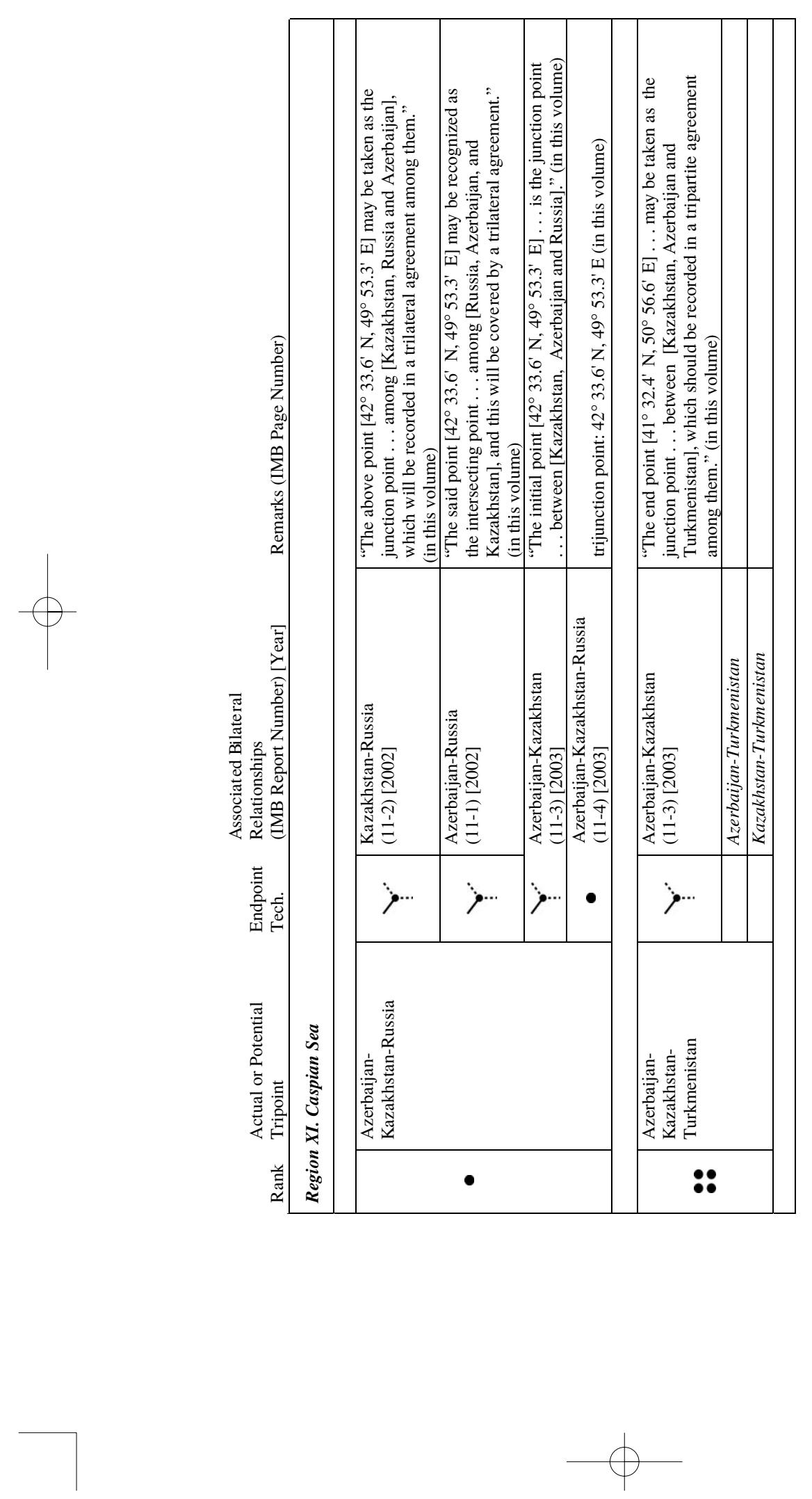